The University of San Francisco

USF Scholarship: a digital repository @ Gleeson Library | Geschke Center

$11-27-2019$

\title{
VIX futures term structure and the expectations hypothesis
}

Ivan Oscar Asensio

University of San Francisco, ioasensio@usfca.edu

Follow this and additional works at: https://repository.usfca.edu/fe

Part of the Finance and Financial Management Commons

\section{Recommended Citation}

Asensio, Ivan Oscar, "VIX futures term structure and the expectations hypothesis" (2019). Finance. 16.

https://repository.usfca.edu/fe/16

This Article is brought to you for free and open access by the School of Management at USF Scholarship: a digital repository @ Gleeson Library I Geschke Center. It has been accepted for inclusion in Finance by an authorized administrator of USF Scholarship: a digital repository @ Gleeson Library I Geschke Center. For more information, please contact repository@usfca.edu. 


\section{QUANTITATIVE \\ FINANCE \\ $\geqslant(-1)^{\circ}$ \\ Quantitative Finance}

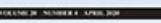

\section{VIX futures term structure and the expectations hypothesis}

Ivan Oscar Asensio

To cite this article: Ivan Oscar Asensio (2020) VIX futures term structure and the expectations hypothesis, Quantitative Finance, 20:4, 619-638, DOI: 10.1080/14697688.2019.1684549

To link to this article: https://doi.org/10.1080/14697688.2019.1684549

Published online: 27 Nov 2019.

Submit your article to this journal

Џlll Article views: 109

Q View related articles $\asymp$

View Crossmark data 


\title{
VIX futures term structure and the expectations hypothesis
}

\author{
IVAN OSCAR ASENSIO* \\ University of San Francisco, School of Management, 101 Howard Street, San Francisco, CA 94105, USA
}

(Received 19 September 2017; accepted 11 October 2019; published online 27 November 2019)

\begin{abstract}
Tests of the expectations hypothesis reveal that the slope of the VIX futures term structure predicts the direction but not the magnitude of the evolution of the short-end of the curve, but predicts neither the direction nor the magnitude of short-term changes in the long-end of the curve. Relative value seeking spread trades, constructed to exploit such violations, deliver excess returns with annualized Sharpe ratios equal or greater than those of volatility-writing strategies deployed by VIX ETN's for a majority of the 32 spread trade combinations tested. I demonstrate that profits from beta-neutral variations of the spread trades, which are not compensation for taking on equity downside risk by design, are propagated by inflows of capital into VIX futures markets, after controlling for factors that measure changes in the availability of hedge fund capital, risk appetite, and momentum. At the heart of profits, and by extension the term structure anomalies, is a disproportionally elevated basis propagated by long VIX demand that enters the futures market through ETN channels.
\end{abstract}

Keywords: Financial futures; Implied volatilities; Quantitative trading strategies; Term structure; Expectations hypothesis; Role of derivatives securities mis-pricing

JEL Codes: B23, G13, G14

\section{Introduction}

The application and relevance of implied volatility to asset pricing, hedging, investment portfolio construction, corporate accounting disclosure, monetary policy development, etc., highlight the importance of validating the accuracy and appropriateness of implied volatility as a measure of risk. The literature that deals with this can be broken down into two key strands. The first investigates the extent implied volatility accurately forecasts the ex post realized volatility of underlying asset prices. Are option premiums justified by the subsequent payouts on those options? If risk premia exist, what can be said about size and persistence? What are the implications for investors, hedgers and arbitrageurs? Important recent work along these lines involving the VIX index has been done by Dew-Becker et al. (2017), Johnson (2016), Ait-Sahalia et al. (2015), and Bekaert and Hoerova (2014).

The second strand evaluates the evolution of implied volatility itself across time. The existence of a term structure implies that the market assigns different prices for different time horizons. For instance, if the term structure is positively (negatively) sloped, does implied volatility at the short-end of the curve rise (fall) as much as predicted? This is the

*Email: ioasensio@usfca.edu analogue of the issue investigated by Shiller (1979) and Froot (1989) for the term structure of interest rates, by Campa and Chang (1995) for currency option implied volatilities, by Mixon (2007) for equity index options, and by Eraker and $\mathrm{Wu}$ (2017) for the VIX.

This paper falls under the second mandate.

The VIX is an index which represents the market's estimate of future realized volatility in the S\&P 500 index (SPX) over a 30-day period. It is expressed in percentage terms per annum, consistent with implied volatility quotes across asset classes. The VIX has been embraced as a risk management vehicle by investors, a barometer for risk aversion by financial markets participants, $\dagger$ and an input to econometric specifications and robustness tests by academic researchers. A higher reading corresponds to greater aversion to market risk, while lower readings are associated with rising risk appetite. The index is derived from a set of out-of-the-money option prices on the SPX across a wide variety of strikes. A negative co-movement between the VIX and the SPX exists by construction. Figure 1 tracks historical price data for both from 2006 to 2018. The correlation is $-76 \%$ for the period highlighted. $\neq$

$\dagger$ The VIX index is commonly referred to as the market's 'fear gauge'.

$\$$ The co-movement is imperfect for reasons highlighted in Section 3 . 


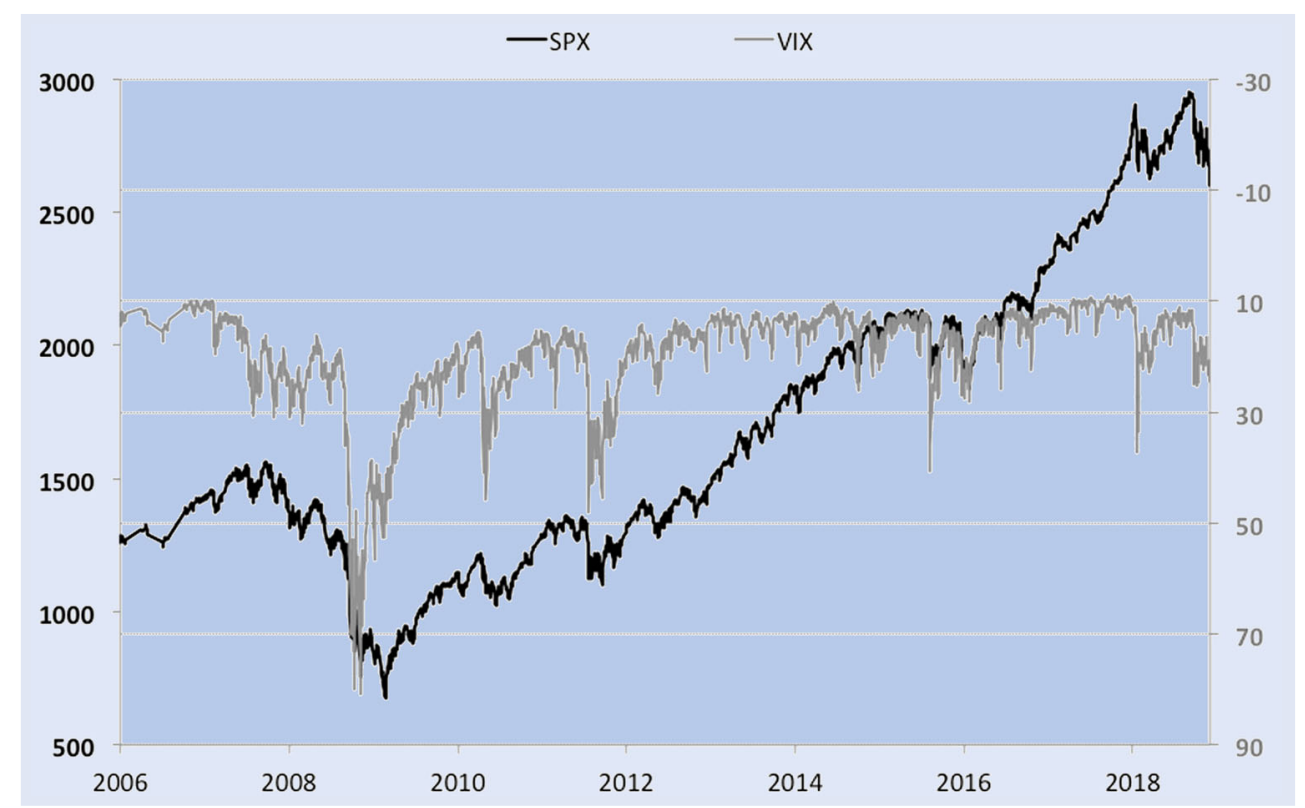

Figure 1. Historical prices for VIX and SPX.

This figure tracks historical price data on the VIX and the SPX, from 2006 to 2018. The strong association between price series is supported quantitatively by a correlation coefficient, based on daily changes, of $-76 \%$ for the entire period. The negative coefficient implies co-movements occur in the opposite direction, by design.

The VIX itself, however, is not an investable asset. Direct replication of the VIX is cumbersome, costly, and in practical terms could not be done without significant tracking error. $\dagger$ Instead, exposure to the VIX index is achieved principally by trading VIX futures, or by buying into exchange-traded notes (ETN's), which themselves derive their value from the trading of VIX futures. structure possesses information content that the VIX term structure does not.§ The former reflects the market's opinion about the evolution of the VIX index itself (future investor risk appetite), while the latter is a projection of ex post realized volatility in the S\&P 500 index. Both bets have gained traction with investors, however. As reported in Dew-Becker et al. (2017), the Commodity Futures Trading Commission's (CFTC) weekly swap report estimates the total vega exposure for variance swaps at the end of 2013 at roughly $\$ 4$ billion. According to VIX futures open interest as of 30-December2013 , the total vega exposure for VIX futures was $\$ 5.26$ billion, on total open interest of 349576 contracts.II

Using the structure of Campa and Chang (1995), I evaluate the expectations hypothesis (EH) on the VIX futures term structure to address two questions. When the VIX term structure is positively (negatively) sloped, does short-end of the curve subsequently rise (fall) as much as predicted according to the linearity with respect to time? And, when the term structure is positive (negative), does the long-end of the curve rise

$\dagger$ One reason is that the VIX is constructed using mid-prices on SPX options. Transactions generally do not occur at mid- prices, as midprices represent an average of the prevailing bid and ask prices. Investors buy options at the offer and sell at the bid.

$\$$ Alexander and Korovilas (2012) furnish a thorough background

$\S$ The VIX index is an expectation of realized volatility in the S\&P 500 index over the next 30 days, in other words, a 30 -day variance swap. The VIX term structure, or long dated variance swap, is a projection of realized volatility beyond 30 days.

II Vega calculation: Number of contracts $\times$ futures prices $\times \$ 1000$. (fall) over the short-term ex post and does it do so by the magnitude predicted? The structure I use allows for testing EH along the curve for each tenor, as opposed to from inceptionto-end for each tenor. This results in a stronger test of $\mathrm{EH}$, as compared to previous work involving the VIX, since it incorporates path-dependency of the index. To the extent term structure represents a forecast, ex ante, of the evolution of the curve, ex post, EH tests reveal this forecast is systematically biased and that the biases narrow with tenor.

The second contribution of this paper is to study the dynamics along the entire VIX futures curve and assess the drivers that contribute to persistence. My investigation considers tenors up to the 8-month contract, whereas prior work on modeling and understanding information content has focused on short-dated contracts. || I construct a relative value strategy involving spread trades which aims to profit from the forecast bias reported, and carry out a set of regressions where factors are regressed on realized profits. I find that long VIX demand, which enters through ETN channels and is concentrated at the short-end of the curve, has maintained the basis for short-dated futures elevated with respect to longer-dated futures. This persistent dynamic is at the heart of the profits, and by extension, the anomalies in the VIX futures term structure reported in expectations hypothesis tests.

This paper is organized as follows. Section 2 provides a brief literature review to highlight and position the contribution of this paper. Section 3 defines the VIX index and VIX futures. Section 4 reviews the structure for testing the expectations hypothesis. Section 5 describes the data and provides return descriptive statistics on VIX futures. Section 6 reports the results of the expectations hypothesis tests. Section 7

\| The one and two-factor dynamic equilibrium models of Eraker and $\mathrm{Wu}$ (2017), for instance, do well at explaining the near and next-term futures returns, however, explanatory power falls with tenor, and the analysis does not go beyond the fifth tenor. 
describes the construct of the various relative value spread trades which aim to profit from EH deviations, and reports the results. Section 8 reports regression results carried out to shed light on persistence of profits and by way of proxy, EH deviations. Section 9 concludes.

\section{Literature review}

The implied volatility literature is rich, and as noted, can be broken down into two key strands. There are papers that address the risk premium (the degree to which option premiums are justified by the subsequent option payouts) and papers that evaluate the expectations hypothesis (the evolution of implied volatility itself). $\dagger$ This paper fits in the latter strata.

\subsection{Risk premia}

Generally speaking, the literature on the risk premia has concluded that option implied volatility contains a significant amount of information about future realized volatility. $\ddagger$ Early work by Fleming (1998), Buraschi and Jackwerth (2001), Coval and Shumway (2001), Bakshi and Kapadia (2002), Pan (2002) and others report that ex ante estimates derived from implied volatility overshoot ex post realized volatility. The various explanations for the existence of the forecast bias§ fall under one of two categories: either the options market is inefficient due to the presence of trading frictions in hedging markets, illiquidity, 'peso problems', limits to arbitrage; or, the option pricing model is incorrect. Option pricing models used in practice, such as the Black-Scholes model, do not allow for a premium for bearing volatility risk. By applying the Heston (1993) model, researchers have attempted to quantify the volatility risk premium as a way to assess the extent to which the forecast bias is due to its omission. Measurement of realized volatility is also a potential source of forecast bias persistence. Poteshman (2002) finds that a more efficient volatility estimator based intra-day five minute returns removed over half of the bias present using daily data. Blair et al. (2001) report up to a four-fold increase in $r$-squared coefficients when going from daily to highfrequency intra-day data.

With regard to the VIX specifically, the field is divided about the existence, relevance, and usefulness of the variance risk premium. Becker and Clements (2008), Bollerslev et al. (2009), Lu and Zhu (2010), Dreschsler and Yaron (2011), Luo and Zhang (2012), Bekaert and Hoerova (2014), Johnson (2016) all found the information

\footnotetext{
$\dagger$ Note, there are some papers in the literature that use the term 'expectations hypothesis' when describing tests that explore the existence of risk premia. However, I define the expectations hypothesis as a test of the extent to which the term structure describes the evolution of the VIX itself, as in Johnson (2016).

$\ddagger$ See Poon and Granger (2003) for a thorough survey of volatility forecasting, based on 93 peer-reviewed research articles.

$\S$ The term forecast bias is used in the literature to denote a deviation from $\mathrm{EH}$, or it is used to convey the existence of risk premia (to the extend implied volatility is viewed as a forecast of future realized volatility, under the risk-neutral measure).
}

content of the VIX and/or its term structure to be valuable in forecasting future realized volatility, equity risk premiums, asset returns, and/or derivative performance. In contrast, Becker et al. (2007) conclude that the VIX does not have forecasting power. Ait-Sahalia et al. (2015) consider a jump risk component in underlying asset prices to develop the VIX term structure and conclude that risk premium exists, but biases and inefficiencies are modest for short time horizons. Dew-Becker et al. (2017) conclude it was costless on average to hedge news about future variance, determining that only purely transitory and unexpected realized variance is priced into the VIX term structure.

\subsection{Expectations hypothesis}

The second key strand of the implied volatility literature, the one addressed in this paper, investigates the evolution of implied volatility itself across time. The existence of a term structure implies that the market places a different level of uncertainty about asset prices for different time horizons. In practice, this results in upward or downward sloping term structures, generally a majority of the time versus a flat or inverted curve. This phenomenon has been the motivation for vast research efforts involving finance theorists, behavioral economists, and hedge funds seeking trading profit opportunities. Results when applied to financial options are mixed. Stein (1989) documents overreactions of the longerdated option prices on the SPX index to changes in shortdated options. Mixon (2007) notes that the implied volatility term structure, as quoted, is based on the risk-neutral measure, whereas the real-world evolution of volatility occurs under a more objective measure. By applying an alternative volatility process, he finds the predictability along the term structure increases, however, not to the extent predicted by the expectations hypothesis. Regarding the VIX specifically, Johnson (2016) rejects EH, but documents the existence of a risk premium and its importance in predicting excess returns. Eraker and Wu (2017) propose a dynamic equilibrium model that explains the risk premia in VIX futures prices for tenors 5 months and under.

Support for EH can be found in the literature. Campa and Chang (1995) develop a well accepted framework for testing EH under the risk-neutral framework, and their results uphold the theory for a narrow set of currency option implied volatilities. Poteshman (2002) and Byoun et al. (2002) find the slope of the implied volatility term structure to have significant predictive ability for future implied volatility of the SPX. Nossman and Wilhelmsson (2009) argue that because the VIX and the S\&P 500 are negatively correlated, VIX futures prices should contain a negative risk premium. The authors find that EH cannot be rejected after such an adjustment. Also they report that risk premium adjusted futures prices provide good forecasting ability of the VIX index with a $73 \%$ hit ratio, albeit only for the shortest tenor. Konstantinidi et al. (2008) and Konstantinidi and Skiadopoulos (2011) demonstrate that VIX futures are predictable by their historical patterns, however the coefficients are too small to generate actual trading profits. 


\section{Preliminaries}

\subsection{VIX index construction}

The VIX index represents the risk-neutral expectation of the realized variance for the SPX index over the next 30-day period

$$
\operatorname{VIX}_{t}=\sqrt{\operatorname{Var}_{t}^{\mathbb{Q}}\left(\ln S_{t+30}\right)}
$$

quoted in annualized percentage terms according to standard market convention, where $S$ represent daily log returns. The methodology for arriving at VIX prices involves computing a weighted average of out-of-the-money (OTM) option prices on the SPX across all strikes for the two nearby maturities. $\dagger$ For expanded detail on the calculation of the VIX index, refer to the CBOE VIX white paper.

\subsection{VIX futures}

The VIX is an index, not an investable asset. The core method for attaining exposure to the VIX is via VIX futures, which began trading on the CBOE on 26-March-2004. There is no cost of carry relationship between the VIX and VIX futures, as is standard between spot and futures prices of other exchangetraded assets such a commodities, currencies, and interest rates. VIX futures prices also do not contain elements related to insurance, storage, and transportation costs. $\S$ The price of a VIX future is a martingale under the risk-neutral expectation

$$
\mathcal{F}_{t}^{j}=E_{t}^{\mathbb{Q}}\left[\mathrm{VIX}_{j}\right]
$$

where $\mathcal{F}$ at $t$ expiring at $j$. Combining equations allows us to express futures prices as

$$
\mathcal{F}_{t}^{j}=E_{t}^{\mathbb{Q}}\left[\sqrt{\operatorname{Var}_{j}^{\mathbb{Q}}\left(\ln S_{j+30}\right)}\right]
$$

the expectation at $t$, of the expectation at $j$ for the realized variance of the SPX index over the period $j+30$. The VIX is a 30 -day forecast of realized $\mathrm{S} \& \mathrm{P} 500$ index variance, thus $\mathcal{F}$ is a forecast of this 30 -day forecast. Figure 2 illustrates the interaction between these concepts.

On 1-February-2012, time $t$, the closing price quotes for the VIX and VIX futures for the 1st and 2nd month expiries were $\mathrm{VIX}_{t}=18.55, \mathcal{F}_{t}^{1}=19.85, \mathcal{F}_{t}^{2}=22.05$, respectively. Thus,

$\dagger$ Maturities occur monthly. In eight out of twelve months in the year, VIX futures settle on the third Wednesday of each month, in the other four months, the futures expire on the fourth Wednesday of the month.

\$ Accessible at www.cboe.com/micro/vix/vixwhite.pdf.

$\S$ See for instance, Fama and French (1998), to appreciate the contrast. Also a number of researches have proposed alternative pricing approaches. Zhang and Zhu (2006), for instance, use the Heston stochastic volatility model to price VIX futures. Zhu and Zhang (2007) value VIX futures by applying a stochastic variance model to the evolution of the VIX itself and to deriving the term structure of forward variance. Lin (2007) uses an affine jumpdiffusion model with jumps in both index and volatility processes to arrive at VIX futures prices. Sepp (2008) applies a similar framework for calibration of both VIX futures and options on the VIX. Zhang and Huang (2010) highlight the importance of dynamics assumptions and parameter estimation by contrasting the results of a number of different approaches.
VIX $_{t}$ is the expectation realized variance of the SPX index over the next 30 days immediately following $t$, and $\mathcal{F}_{t}^{1}, \mathcal{F}_{t}^{2}$ and so on (for the longer-dated expiries) are forecasts of the forecasts at $j$ of realized variance of the SPX.II The horizontal dashed arrows in figure 2 represent the period over which such expectations apply.

The focus of this paper is not to explore the extent to which the VIX accurately forecasts the future realized variance of the SPX index. Rather, the objective is to understand and characterize the evolution of the expectations themselves. For illustrative purposes, a similar distinction can be made within the insurance industry. For instance, changes in the expectations of floods in New York City can be gauged by changes in the price level of flood insurance premiums. $\|$ An analysis of the cumulative premiums taken in by insurance companies measured against subsequent payouts is also important, however, that is a separate question. The focus of this paper is to understand and characterize the changes in premiums, based on premiums charged for different periods in the future.

\section{Structure}

I use the expectations hypothesis $(\mathrm{EH})$ to evaluate the information content of VIX futures, that is, the extent to which the evolution of the VIX index ex post is described by the VIX futures term structure, ex ante, along various tenors. I use formulation based on Campa and Chang (1995). The structure tests $\mathrm{EH}$ along the curve for each tenor, as opposed to from inception-to-end for each tenor. This results in a stronger test of EH since it incorporates path-dependency of the index over the test period. In addition, I test EH using a second formulation which evaluates short-term movements along the long-end of the curve, based on the term structure slope ex ante.

\subsection{Background}

Campa and Chang (1995) derive the formulation for testing EH under three key assumptions: (1) volatility is stochastic, (2) the underlying asset and its volatility are uncorrelated, and (3) there is no volatility risk premium. The first assumption is a departure from the Black Scholes framework, and a well accepted concept within option pricing theory. As Hull and White (1987) demonstrate, the discrepancy between option prices using stochastic versus static volatility is independent of the level of volatility but increases with the time to maturity. With regard to the second assumption, Mixon (2007) tests $\mathrm{EH}$ using a similar formulation and points out that non-zero correlation would not present a problem provided there is no material wedge between the average expected volatility and the implied volatility for ATM options. This result is applicable to VIX futures by construction, according to equation (2).

II Note $\mathcal{F}_{t}^{1}$ references the futures contract with the nearest expiry to $t$. As time goes by, $\mathcal{F}_{t}^{1}$ will naturally reference different individual futures contracts as contracts expire and roll down.

$\|$ Other factors that would contribute to flood insurance premiums are cost of capital, interest rates, the general health of the insurance industry, disruption by insurtech players, etc. 


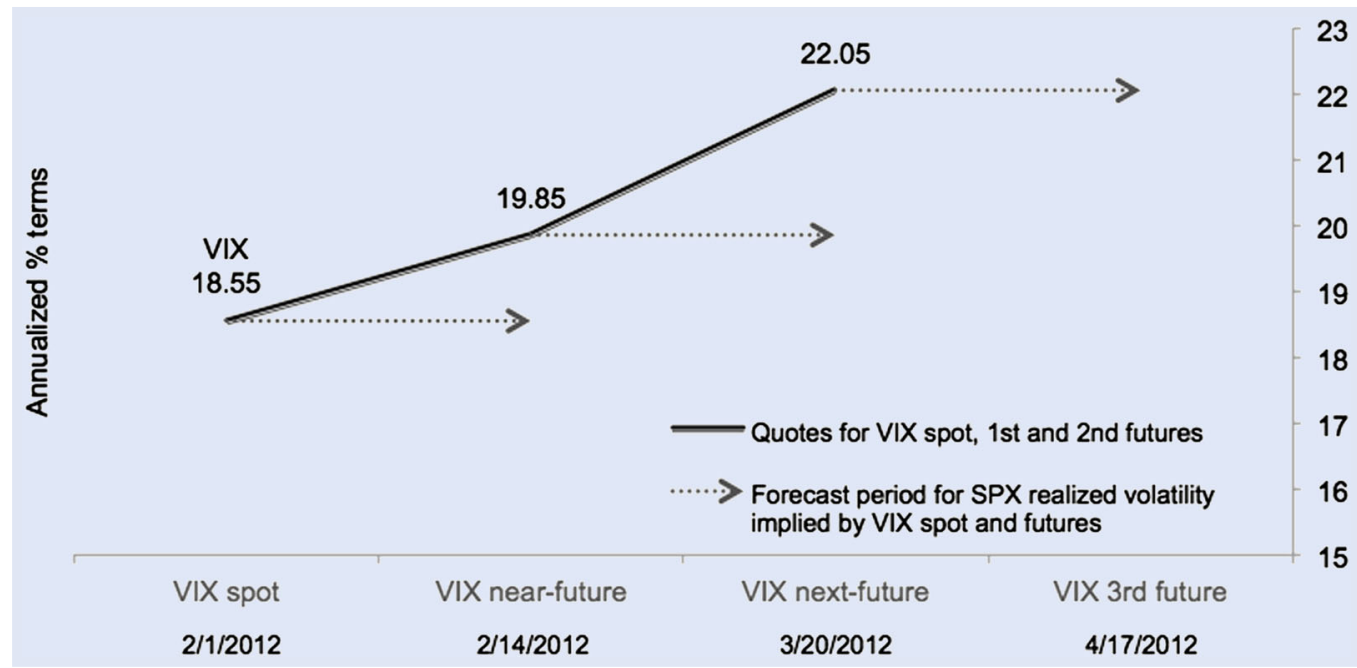

Figure 2. VIX, VIX futures, and expectations of SPX realized volatility illustrated.

This figure illustrates the interaction between the VIX, VIX futures, and expectations of SPX realized volatility. On 1-February-2012, time $t$, the closing price quotes for the VIX and VIX futures for the 1st and 2nd month expiries were $\operatorname{VIX}_{t}=18.55, \mathcal{F}_{t}^{1}=19.85, \mathcal{F}_{t}^{2}=22.05$, respectively. Thus, VIX $_{t}$ is the expectation realized variance of the SPX index over the next 30 days immediately following $t$, and $\mathcal{F}_{t}^{1}, \mathcal{F}_{t}^{2}$ and so on (for the longer-dated expiries) are forecasts of the forecasts at $j$ of realized variance of the SPX. The horizontal dashed arrows in figure 2 represent the period over which such expectations apply.

Finally, the last assumption is that volatility risk premium is zero. Campa and Chang do not test this assumption directly, but establish that if risk premia exists but not considered, the bias from omitted variables in their specification would contribute to further support of EH.

\subsection{Constructing the $\mathrm{EH}$ test}

The Campa and Chang formulation can be applied to ascertain whether the long-end of the VIX futures curve is consistent with the movements along the short-end of the curve, based on the linearity of variance with respect to time. By definition this means

$$
E_{0}\left[T_{2}\left(\mathcal{F}_{0}^{2}\right)^{2}\right]=E_{0}\left[T_{1}\left(\mathcal{F}_{0}^{1}\right)^{2}\right]+E_{0}\left[\left(T_{2}-T_{1}\right)\left(\mathcal{F}_{1}^{2}\right)^{2}\right],
$$

implying that if today the 1 st and 2 nd expiry futures prices are $14 \%$ and $16 \%$ respectively, the expected 1 st expiry futures price next month will be $17.77 \% . \dagger$ Furthermore, by the law of iterated expectations

$$
E_{0}\left[\left(\mathcal{F}_{1}^{2}\right)^{2}\right]=E_{1}\left[\left(\mathcal{F}_{1}^{2}\right)^{2}\right]+u_{1}
$$

with random error term $u$. Combining equations yields

$$
\left(T_{2}-T_{1}\right)\left(\mathcal{F}_{1}^{2}\right)^{2}=\left(\frac{\theta_{1}}{\theta_{2}}\right)^{2} T_{2}\left(\mathcal{F}_{0}^{2}\right)^{2}-T_{1}\left(\mathcal{F}_{0}^{1}\right)^{2}+u_{1},
$$

which can be further reduced to

$$
\left(\mathcal{F}_{1}^{2}\right)^{2}=2\left(\frac{\theta_{1}}{\theta_{2}}\right)^{2}\left(\mathcal{F}_{0}^{2}\right)^{2}-\left(\mathcal{F}_{0}^{1}\right)^{2}+u_{1}
$$

assuming successive futures prices such that $T_{2}=2 T_{1}$. This equation describes the expectations hypothesis in futures

$\dagger\left(\frac{1}{12}\right) 0.14^{2}+\left(\frac{1}{12}\right) 0.1777^{2}=\left(\frac{2}{12}\right) 0.16^{2}$ prices squared. Generalizing for $k$ periods of length $m$ yields

$$
\left(\mathcal{F}_{0}^{k m}\right)^{2}=\left(\frac{1}{k}\right) E_{0}\left[\sum_{i=0}^{k-1}\left(\mathcal{F}_{i}^{(i+1) m}\right)^{2}\right]\left(\frac{\theta_{k m}}{\theta_{m}}\right)^{2}
$$

This equation says that the current long-dated volatility quote squared equals the average of the current and expected future short-dated volatility quotes squared. In other words, the slope of the VIX futures term structure is informative about where implied volatility squared will be in the future. In the original formulation, Campa and Chang apply the simplifying assumption, $\theta_{k m} / \theta_{m}=1$. Since the level of volatility follows a near unit-root process, (8) is tested in terms of long-short spread rather than using variance levels directly. Subtracting the near or first future squared to both sides yields the Campa and Chang testable equation for the expectations hypothesis on the VIX term structure such that (8) becomes

$$
\begin{aligned}
& \left(\frac{1}{k}\right) \sum_{i=0}^{k-1}\left[\left(\mathcal{F}_{i}^{(i+1) m}\right)^{2}-\left(\mathcal{F}_{0}^{m}\right)^{2}\right] \\
& =\alpha_{0}+\beta_{0}\left[\left(\mathcal{F}_{0}^{k m}\right)^{2}-\left(\mathcal{F}_{0}^{m}\right)^{2}\right]+\sum_{i=1}^{k-1} u_{i}
\end{aligned}
$$

where $u_{i}$ represent the expectational errors. The projection of short-dated VIX futures comes from VIX futures prices squared at time 0 , which enter through the right-hand side of equation. Figure 3 shows two possible expectations hypothesis paths for the near-term contract (first term on the left-hand side of equation) based on the VIX futures price curve going out 8 months, ex ante. For expository purposes, all elements are expressed in volatility terms, the square root of variance.

$\$$ This results in a futures term structure of $j=k m$, where $m$ is generally 1 month. 


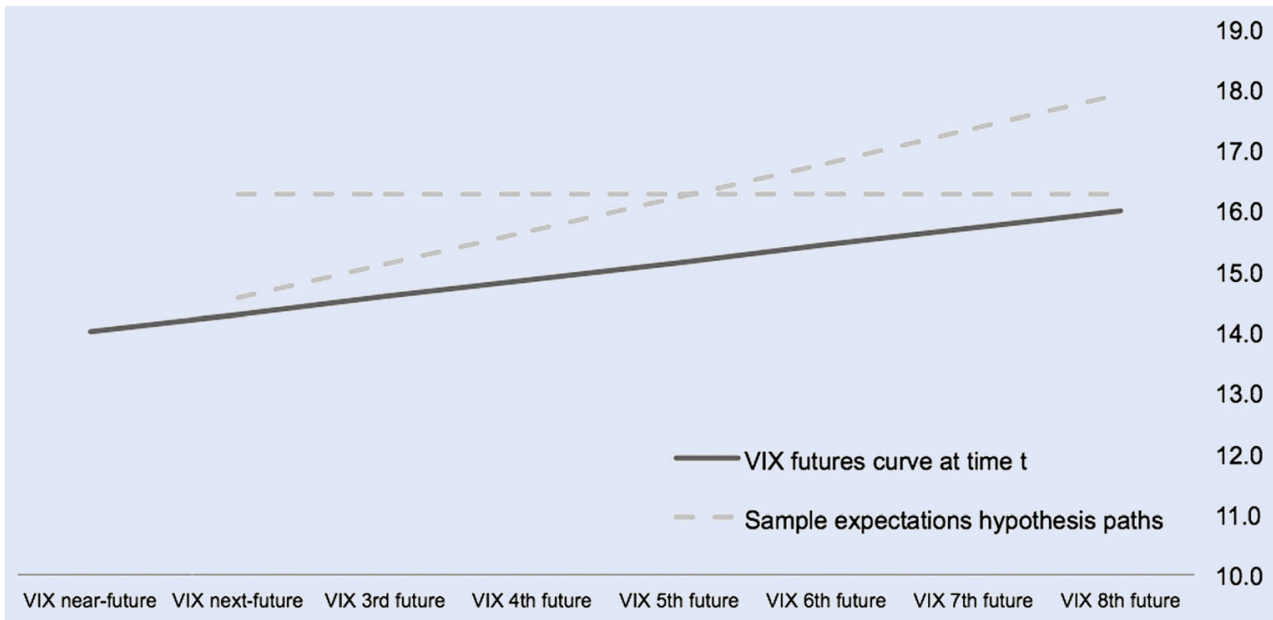

Figure 3. VIX futures curve and sample expectations hypothesis paths.

This figure shows two possible expectations hypothesis paths for the near-term contract based on the VIX futures price curve going out 8 months. For expository purposes, all elements are expressed in volatility terms, the square root of variance. The VIX futures curve prices will differ from the possible expectations path prices. When the slope of the VIX futures curve is positive, the projected path for the short-dated futures price, based on the linearity of variance, will generally be above the VIX futures curve. Many paths are possible. EH is upheld in situations where the curve slope ex ante equals the average short-dated volatility changes ex post.

When the slope of the VIX futures curve is positive, the projected path for the short-dated futures price, based on the linearity of variance, will generally be above the VIX futures curve. Many paths are possible. EH is upheld in situations where the curve slope ex ante equals the average shortdated volatility changes ex post, or econometrically when the hypothesis test $\alpha_{0}=0$ and $\beta_{0}=1$ is not rejected.

\subsection{Alternative EH test}

A second interpretation of $\mathrm{EH}$ in this context is to evaluate whether short-term changes in the long-end of the curve are consistent with the current spread between the short and the long-end. Subtracting equation (8) from the same equation with a one month lead and once again subtracting out the first future squared to both sides yields the expression

$$
\begin{aligned}
& \left(\mathcal{F}_{m}^{k m}\right)^{2}-\left(\mathcal{F}_{0}^{k m}\right)^{2} \\
& =\alpha_{0}+\beta_{0}\left(\frac{1}{k-1}\right)\left[\left(\mathcal{F}_{0}^{k m}\right)^{2}-\left(\mathcal{F}_{0}^{m}\right)^{2}\right]+u_{m},
\end{aligned}
$$

noting that $\theta_{k m} / \theta_{m}=1$. Both tests together will provide a comprehensive evaluation of the information content in the VIX futures term structure.

\section{Data and return descriptive statistics}

The dataset includes daily closing prices for the SPX and VIX indices, VIX futures prices, and implied volatility for options on the VIX index from January 2006 to December 2018. All data on the VIX are expressed in percentage terms per annum, consistent with implied volatility quotes across asset classes. The original source of this data is the CBOE, however, they were gathered through Bloomberg. At any point in time, there is a set of VIX futures contracts that expire at specific dates in the future. The near or 1st future expires within one month, the next or 2nd future expires in the following calendar month and so on. When VIX futures were launched on 26-March-2004, there were only four futures contracts trading on any given day. In 2006, more contracts were introduced such that today there are 8 or more contracts outstanding at any given time. In order to utilize as much history as possible in constructing the term structure, whilst minimizing over-reliance on interpolation and extrapolation to fill missing values, I use the first 8 months of maturities from January 2006. Table 1 contains descriptive statistics on the VIX index, the VIX futures curve for tenors up to 8 months, and implied volatility for at-themoney options written on the VIX index. The frequency of the data is daily and only active trading days, no weekends or holidays, are considered for each tenor of VIX futures.

The average figures demonstrate there is a tendency for the VIX futures curve to be upward sloping. In addition, from panel 1 it is evident that both the price ranges (difference between high and low readings) and the volatility of the actual prices themselves decrease as the time to maturity increases. The intuition for this phenomenon is as follows. Consistent with other term structure models of VIX futures, the long end of the futures curve is less volatile because of mean reversion of the underlying VIX index, under $\mathbb{Q}$. That is, the long-end of the curve is less responsive to changes in spot because the longer the maturity of the forward, the closer the forecast will be to the long-term mean. Note, this is confirmed by the downward sloping implied volatility term structure for options on the VIX. Skewness readings are in line with implied volatilities in other asset classes. Kurtosis figures indicate fat tails for the underlying VIX.

Table 2 shows constant-maturity VIX futures return descriptive statistics. Due to the well-known biases that may arise when computing investment performance, $\dagger$ I report both arithmetic and geometric returns following the structure of

$\dagger$ See Blume (1974). Arithmetic returns from high-frequency data (i.e. daily) may overstate the performance of buy and hold strategies, 
Table 1. Descriptive statistics for VIX, VIX futures, implied volatility on options on the VIX (Jan 2006-Dec 2018).

Panel 1: VIX index, VIX futures prices (\%)

\begin{tabular}{|c|c|c|c|c|c|c|c|c|c|}
\hline & $\begin{array}{l}\text { VIX } \\
\text { VIX }\end{array}$ & $\begin{array}{l}\text { Near future } \\
\qquad \mathcal{F}^{1}\end{array}$ & $\begin{array}{l}\text { Next future } \\
\mathcal{F}^{2}\end{array}$ & $\begin{array}{c}\text { 3rd future } \\
\mathcal{F}^{3}\end{array}$ & $\begin{array}{l}\text { 4th future } \\
\mathcal{F}^{4}\end{array}$ & $\begin{array}{c}\text { 5th future } \\
\mathcal{F}^{5}\end{array}$ & $\begin{array}{c}\text { 6th future } \\
\mathcal{F}^{6}\end{array}$ & $\begin{array}{c}\text { 7th future } \\
\mathcal{F}^{7}\end{array}$ & $\begin{array}{c}\text { 8th future } \\
\mathcal{F}^{8}\end{array}$ \\
\hline Average & 19.2 & 19.7 & 20.5 & 21.3 & 21.7 & 22.1 & 22.4 & 22.6 & 22.5 \\
\hline Max & 80.9 & 67.9 & 59.5 & 54.6 & 50.4 & 47.8 & 46.0 & 44.5 & 44.0 \\
\hline Min & 9.14 & 9.60 & 11.3 & 12.2 & 13.0 & 13.5 & 13.9 & 14.4 & 14.3 \\
\hline Std Dev & 9.44 & 8.60 & 7.72 & 7.14 & 6.69 & 6.36 & 6.06 & 5.82 & 5.44 \\
\hline Skewness & 2.41 & 2.13 & 1.76 & 1.52 & 1.29 & 1.14 & 1.03 & 0.94 & 1.15 \\
\hline \multirow[t]{3}{*}{ Kurtosis } & 7.88 & 5.77 & 3.86 & 2.85 & 1.80 & 1.15 & 0.73 & 0.46 & 1.02 \\
\hline & \multicolumn{9}{|c|}{ Percentage of time futures spread to fix was positive (\%) } \\
\hline & & 74 & 81 & 81 & 82 & 82 & 82 & 84 & 86 \\
\hline$n$ obs & 3261 & 3261 & 3242 & 3145 & 3106 & 3075 & 3019 & 2871 & 2579 \\
\hline
\end{tabular}

Panel 2: Implied volatility of at-the-money VIX options (\%)

\begin{tabular}{lccc}
\hline & 1-month & 2-month & 6-month \\
\hline Average & 78.2 & 69.0 & 62.4 \\
Max & 176.7 & 124.4 & 108.8 \\
Min & 38.0 & 37.5 & 36.3 \\
Std Dev & 17.9 & 13.5 & 10.7 \\
Skewness & 0.91 & 0.71 & 0.56 \\
Kurtosis & 1.52 & 0.75 & 0.34 \\
\hline
\end{tabular}

Note: This table, panel 1, contains descriptive statistics for VIX and VIX futures. The frequency of this data is daily. The average figures demonstrate there is a tendency for the VIX futures curve to be upward sloping, validated by the statistics on percentage of time futures to VIX spread was positive. In addition, from panel 1 it is evident that both the price ranges (difference between high and low readings) and the volatility of the actual prices themselves decrease as the time to maturity increases. Consistent with other term structure models of VIX futures, the long end of the futures curve is less volatile because of mean reversion of the underlying VIX index, under $\mathbb{Q}$. That is, the long-end of the curve is less responsive to changes in spot because the longer the maturity of the forward, the closer the forecast will be to the long-term mean. Note, this is confirmed by the downward sloping implied volatility term structure for options on the VIX in panel 2. Skewness readings are in line with implied volatilities in other asset classes. Kurtosis figures indicate fat tails for the underlying VIX. The number of observations $n$ denotes the days for which there was an active contract.

Table 2. Constant-maturity VIX futures returns (Jan 2006-Dec 2018).

\begin{tabular}{|c|c|c|c|c|c|c|c|c|}
\hline & $\mathcal{F}^{1}$ & $\mathcal{F}^{2}$ & $\mathcal{F}^{3}$ & $\mathcal{F}^{4}$ & $\mathcal{F}^{5}$ & $\mathcal{F}^{6}$ & $\mathcal{F}^{7}$ & $\mathcal{F}^{8}$ \\
\hline \multicolumn{9}{|c|}{ Daily arithmetic returns (\%) } \\
\hline Average & -0.146 & -0.122 & -0.077 & -0.057 & -0.054 & -0.045 & -0.037 & -0.019 \\
\hline $\operatorname{Max}$ & 112.5 & 86.8 & 84.9 & 57.8 & 14.6 & 24.7 & 43.6 & 17.3 \\
\hline Min & -28.0 & -24.7 & -28.0 & -20.2 & -9.24 & -9.19 & -20.7 & -9.76 \\
\hline Std Dev & 5.24 & 3.75 & 3.16 & 2.58 & 2.12 & 2.00 & 2.07 & 1.76 \\
\hline \multicolumn{9}{|c|}{ Annualized arithmetic returns (\%) } \\
\hline Average & -38.1 & -31.8 & -20.0 & -14.9 & -14.1 & -11.7 & -9.51 & -4.96 \\
\hline \multicolumn{9}{|c|}{ Annualized geometric returns (\%) } \\
\hline Average & -49.7 & -37.5 & -25.9 & -19.2 & -16.5 & -14.0 & -11.8 & -6.51 \\
\hline
\end{tabular}

Note: This table shows constant maturity VIX futures return descriptive statistics. Due to the well-known biases that may arise when computing investment performance, I report both arithmetic and geometric returns following the structure of Eraker and Wu (2017). I confirm both the persistence of the negative return profile of VIX futures in general and the notable improvement of returns (i.e. less negative) for longer maturities.

Eraker and $\mathrm{Wu}$ (2017). $V_{t}$ represents the value at time $t$ of a portfolio $p$ that aims to maintain a constant-tenor futures position by rolling futures contracts at daily closing prices, where $V_{t}=V_{t-1}\left(1+r_{t}\right)$ and $r_{t}$ is the daily return defined as $r_{t}=\mathcal{F}_{t}^{j} / \mathcal{F}_{t-1}^{j}-1$ for a given futures tenor $j$. Thus, the average daily arithmetic return is $(1 / n) \sum_{t} r_{t}$, the annualized arithmetic return is $(1 / n) \sum_{t} r_{t} \times 260$ and the annualized geometric return is $\left(V_{T} / V_{0}\right)^{260 / T}-1$ for $n$ days in the sample covering the period $T$.

while geometric return calculations tend to understate the actual performance.
The negative average rates of return for VIX futures has been reported in previous studies. Eraker and Wu (2017) do so, based on the first 5 months of futures maturities. Johnson (2016) arrives at the same result by evaluating 1 and 3-month tenors. Nossman and Wilhelmsson (2009) concur but evaluate the first future only. One contribution of this paper is to incorporate as much of the VIX futures term structure as possible. In doing so, I confirm both the persistence of the negative return profile of VIX futures in general and the notable improvement of returns (i.e. less negative) for longer maturities. Recognizing that arithmetic returns may 


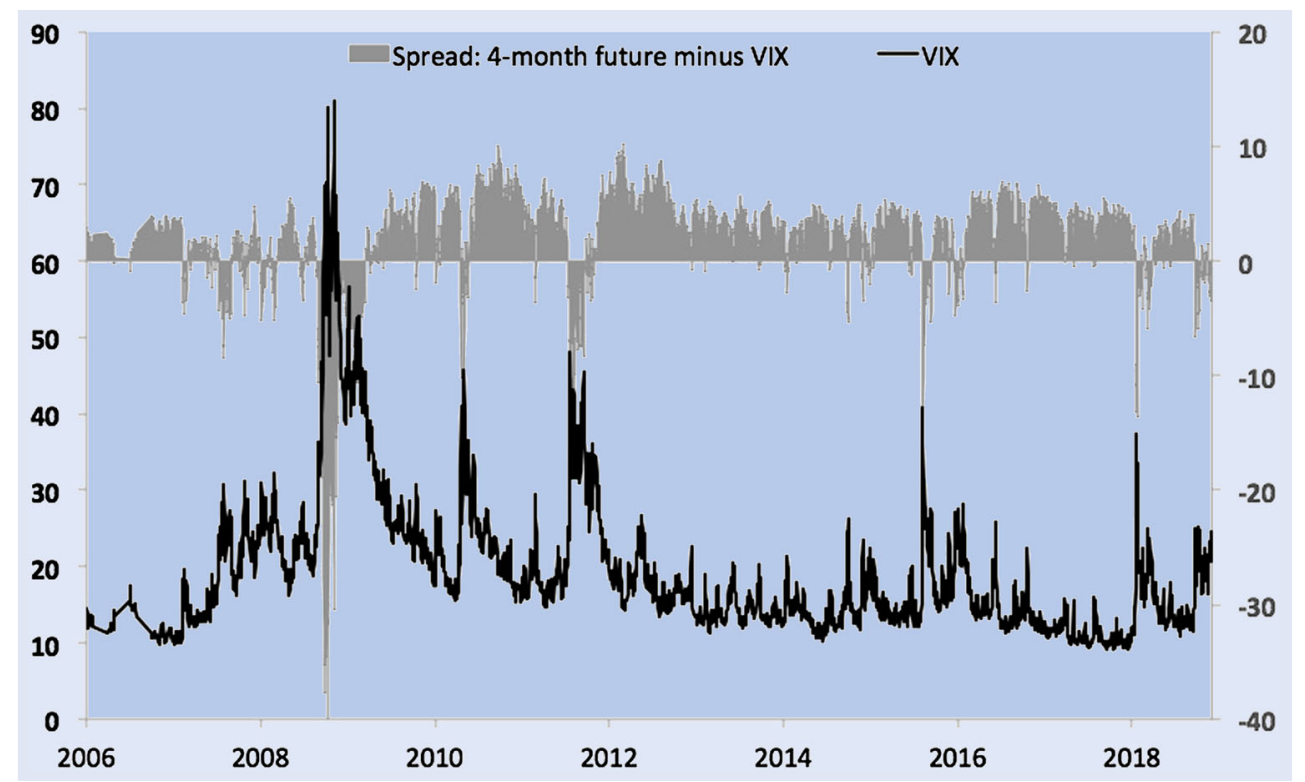

Figure 4. Spread between 4-month VIX futures versus the VIX.

This figure tracks the spread between 4-month VIX futures (left axis) and the underlying VIX (right axis) for the entire sample period. A few observations worth noting. For a majority of the time, the differential is positive, as noted in table 1 for the entire term structure. The near-term futures contract has a positive spread to VIX $74 \%$ of the time, the next-term futures has a positive spread $81 \%$ of the time, and so on increasing with tenor. The next important observation is that the spread went steeply negative during the height of the 2008 credit crisis and then materially negative in the latter half of 2011 when Euro zone crisis fears peaked. And three, the average spread, when positive, was substantially greater after 2011, a period which would be characterized by the proliferation of VIX exchange-traded notes (ETN's).

overstate the performance of buy and hold strategies when the skew of individual high-frequency returns favors positive versus negative returns, I also report geometric returns. Geometric returns, in contrast, have the tendency to understate performance. For example, if a stock falls $10 \%$ on day 1, it would have to rise by 'more' than $10 \%$ on day 2 in order to get back to the original price. In other words, the return sequence of down $10 \%$ and up $10 \%$ would translate into an average geometric return of $-1 \%, \dagger$ despite the 'true' average being zero. Compounding is a confounder, nonetheless it is valuable data point when evaluated against the arithmetic metrics.

The evolution of the VIX futures curve across time is important. Figure 4 tracks the spread or differential between 4-month VIX futures and the underlying VIX, a few observations worth noting.

For a majority of the time, the differential is positive, as noted in table 1 for the entire term structure. The near-term futures contract has a positive spread to VIX $74 \%$ of the time, the next-term futures has a positive spread $81 \%$ of the time, and so on increasing with tenor. The next important observation is that the spread went steeply negative during the height of the 2008 credit crisis and then materially negative in the latter half of 2011 when Euro zone crisis fears peaked. And three, the average spread, when positive, was substantially greater after 2011, a period which would be characterized by the proliferation of VIX exchange-traded notes (ETN's).

$\dagger$ Calculation: $(1-10 \%) \times(1+10 \%)=-1.0 \%$.

\section{Expectations hypothesis tests}

I evaluate the expectations hypothesis on the VIX futures term structure to address two questions. When the VIX term structure is positively (negatively) sloped, does short-tend of the curve subsequently rise (fall) as much as predicted according to the linearity with respect to time? And, when the term structure is positive (negative), does the long-end of the curve rise (fall) ex post and does it do so by the magnitude predicted? The former will be investigated using EH test 1 and the latter with EH test 2.

\subsection{Expectations hypothesis test 1}

For the first test, I evaluate the long-short spread at time $t=0$ for tenors 2 through 8 against changes in the short-end of the VIX futures curve, specifically the near-term futures, over subsequent $k-1$ periods. There are seven different tests, starting with the 8 to 1 -month spread on the evolution of the 1-month (labeled 8-1 on 1), 7 to 1-month spread on the subsequent movements of the 1-month (labeled 7-1 on 1), and so on. The long-short spread is an unbiased predictor if $\alpha=0$ and $\beta=1$. This would imply that for every unit of variance in the long-short spread today, we would expect one unit of variance movement ex post for the near-term VIX futures contract. Rejections of this joint hypothesis test will be reported at the $5 \%$ level. Table 3, panel 1, contains the results.

Test results reveal that the long-short spread predicted the direction of the subsequent move in the short-end of the curve for all tenors, since all beta coefficients are positive, but not 
Table 3. Expectations hypothesis on the VIX futures term structure (Jan 2006-Dec 2018).

Panel 1: Expectations hypothesis test 1

\begin{tabular}{|c|c|c|c|c|c|c|c|}
\hline \multicolumn{8}{|c|}{$\left(\frac{1}{k}\right) \sum_{i=0}^{k-1}\left[\left(\mathcal{F}_{i}^{(i+1) m}\right)^{2}-\left(\mathcal{F}_{0}^{m}\right)^{2}\right]=\alpha_{0}+\beta_{0}\left[\left(\mathcal{F}_{0}^{k m}\right)^{2}-\left(\mathcal{F}_{0}^{m}\right)^{2}\right]+\sum_{i=1}^{k-1} u_{i}$} \\
\hline & $8-1$ on 1 & $7-1$ on 1 & $6-1$ on 1 & $5-1$ on 1 & 4-1 on 1 & 3-1 on 1 & $2-1$ on 1 \\
\hline$\alpha_{0}$ & $-0.006^{*}$ & $-0.004^{*}$ & $-0.002^{*}$ & $-0.001^{*}$ & $0.000^{*}$ & $0.000^{*}$ & $0.000^{*}$ \\
\hline (s.e.) & $(0.006)$ & $(0.007)$ & $(0.006)$ & $(0.005)$ & $(0.004)$ & $(0.003)$ & $(0.002)$ \\
\hline$\beta_{0}$ & $0.619^{*}$ & $0.546^{*}$ & $0.459^{*}$ & $0.401^{*}$ & $0.347^{*}$ & $0.172^{*}$ & $-0.104^{*}$ \\
\hline (s.e.) & $(0.124)$ & $(0.106)$ & $(0.119)$ & $(0.118)$ & $(0.112)$ & $(0.158)$ & $(0.100)$ \\
\hline$R$-squared & 0.25 & 0.21 & 0.16 & 0.13 & 0.100 & 0.03 & 0.02 \\
\hline$N$ & 2398 & 2690 & 2838 & 2893 & 2925 & 2964 & 3061 \\
\hline \multicolumn{8}{|c|}{ Panel 2: Expectations hypothesis test 2} \\
\hline \multicolumn{8}{|c|}{$\left(\mathcal{F}_{m}^{k m}\right)^{2}-\left(\mathcal{F}_{0}^{k m}\right)^{2}=\alpha_{0}+\beta_{0}\left(\frac{1}{k-1}\right)\left[\left(\mathcal{F}_{0}^{k m}\right)^{2}-\left(\mathcal{F}_{0}^{m}\right)^{2}\right]+u_{m}$} \\
\hline & $8-1$ on 8 & $7-1$ on 8 & $6-1$ on 8 & $5-1$ on 8 & $4-1$ on 8 & $3-1$ on 8 & $2-1$ on 8 \\
\hline$\alpha_{0}$ & $-0.0003^{*}$ & $0.00006^{*}$ & $0.0002^{*}$ & $0.0002^{*}$ & $0.0006^{*}$ & $0.0006^{*}$ & $0.0007^{*}$ \\
\hline (s.e.) & (0.006) & $(0.007)$ & $(0.006)$ & $(0.005)$ & $(0.004)$ & $(0.003)$ & $(0.002)$ \\
\hline$\beta_{0}$ & $-0.219^{*}$ & $-0.554^{*}$ & $-0.581^{*}$ & $-0.616^{*}$ & $-0.700^{*}$ & $-0.725^{*}$ & $-0.792^{*}$ \\
\hline (s.e.) & (0.124) & (0.106) & (0.119) & $(0.118)$ & $(0.112)$ & $(0.158)$ & $(0.100)$ \\
\hline$R$-squared & 0.02 & 0.09 & 0.11 & 0.14 & 0.16 & 0.19 & 0.24 \\
\hline$N$ & 2398 & 2690 & 2838 & 2893 & 2925 & 2964 & 3061 \\
\hline
\end{tabular}

Notes: *Indicates rejection at the $5 \%$ level of joint null hypothesis $\alpha=0$ and $\beta=1$.

This table contains the results of the expectations hypothesis tests on the VIX futures term structure. Panel 1 contains results of EH test 1 , regressions of ex post changes in the short-end of the curve on the ex ante term structure, while panel 2 contains the results of EH test 2 , regressions of ex post changes in the long-end of the curve on the ex ante term structure. Asterisk $\left(^{*}\right)$ denotes rejection of joint hypothesis test, $\alpha=0$ and $\beta=1$, at the $5 \%$ level.

the magnitude. The $\beta$ coefficient reading of 0.619 for the 8 month VIX futures term structure test implies that 10 variance units in ex ante long-short spread are associated with a rise in the near-term futures contract of 6.19 variance units over the subsequent 7-month period, with an $r$-squared of 0.25 . In other words, the ex ante term structure overshot in its prediction of the ex post movement of the short-end of the curve. Comparing the results across tenors reveals an important pattern. The $\beta$ coefficients get farther away from 1.0 as the tenor shortens. Also the fit, described by the $r$-squared readings, is proportionally worse for shorter tenors. These findings are consistent with the mean-reversion quality of the underlying VIX index, under $\mathbb{Q}$. Longer maturity contract prices represent more accurate forecasts, versus shorter-term contracts, of the long-term mean established, ex post.

The intuition for this result is also supported by a wellknown stylized fact about option-pricing. The cost of holding an option, measured on a per day basis, is lower for longerdated options. All else equal, option prices grow with tenor at a rate approximately equal to the square root of time, prices are not linear in time. $\dagger$ This theoretical underpinning is supported in practice. Hedgers and speculators with shorter-term goals are willing to pay more, on a per day basis, to hold options. A higher value is placed on 'gamma', a market-term

$\dagger$ For instance, the cost of a six-month at-the-money option is not two-times the cost of the three-month at-the-money option, both at time $t$, all else equal. Assuming a flat Black Scholes implied volatility term structure, it is less than two-times, or specifically $\sqrt{\frac{1}{2}}<(2 \times$ $\left.\sqrt{\frac{1}{4}}\right)$. for portfolios of short-dated options, which can go in or out of the money rapidly, more so than longer-dated equivalents.

\subsection{Expectations hypothesis test 2}

For the second test, I evaluate the long-short spread at time $t=0$ for tenors 2 through 8 , expressed in units of variance per month, against changes in the long-end of the VIX futures curve over subsequent 1-month periods. Again, there are seven different tests. The long-short spread is an unbiased predictor if $\alpha=0$ and $\beta=1$. This would imply that for every unit of variance in the long-short spread today, we would expect one unit of variance movement ex post for the longterm VIX futures contract. Rejections of this joint hypothesis test will be reported at the $5 \%$ level. Table 3 , panel 2 , contains the results of this test.

Without exception, the EH test is rejected for all tenors. The VIX term structure fails to predict both direction and the magnitude. A $\beta$ reading of -0.219 for the $8-1$ on 8 test (tests the 8 to 1-month spread on the subsequent 1-month move in the 8 -month contract) tells us that for every 10 units of average monthly variance in the long-short spread, this corresponds to a fall of 2.19 units of variance for the 8-month over a 1-month period. The $\beta$ is negative for all tenors, but the magnitude rises with shorter tenors ( $\beta$ 's get more negative). This result is consistent with the negative return premia for VIX futures documented in this paper and others. For example, the VIX futures term structure going out 8 months is positive $86 \%$ of the time (2006-2018), signaling that the ex-post move in the

$\$$ Explicitly, gamma is the rate of change of delta, the sensitivity of the option price to changes in spot rates. 
long-end of the curve should be higher, also implying that a premium is paid over the underlying VIX index to establish a long position. The test results describe the tendency for the long-end of the curve to fall, ex post, thus yielding negative returns, on average, for long positions. This tendency is stronger for shorter-tenors, and this is validated by the larger losses for shorter tenors in table 2.

\subsection{Summary}

To recap, tests of the expectations hypothesis reveal four key findings about the information content of the VIX futures term structure for the period of 2006-2018: (1) Term structure is an accurate predictor of the direction of the ex post evolution of the short-end of the curve, however, (2) the term structure overshoots in its prediction of the ex post movement of the short-end of the curve, (3) with regard to movements of the long-end of the curve, the term structure fails to predict both direction and magnitude, and (4) the predictive power of the term structure, related to both the evolution of the short-end and ex post movements in the long end, worsens with shorter tenors.

\section{VIX futures spread trades}

The negative return premia of VIX futures assets, which has been documented, characterized and quantified in this and in previous papers, is a practical manifestation of the expectations hypothesis test results. Prior work on modeling and understanding information content has focused on shortdated contracts. The one and two-factor dynamic equilibrium models of Eraker and Wu (2017), for instance, do well at explaining the near and next-term futures returns, however, explanatory power falls with tenor, and the analysis does not go beyond the fifth tenor. The second contribution of this paper, then, is to study the dynamics along the entire VIX futures curve (out to 8 months) and assess the drivers that contribute to the persistence of such behaviors.

To the extent term structure represents a forecast of the evolution of the curve, ex post, we know this forecast is systematically biased and that the biases narrow with tenor. Excess returns may be realized through spread trades which sell the short-end of the curve, where bias is persistently greater, against buying the long-end of the curve, where the bias is smaller. $\dagger$ I will construct two varieties of spread trades, exposure-neutral and beta-neutral. The former allocates the same amount of capital to the long and the short position at inception, while the latter allocates capital based on sensitivity (beta) to the VIX index at a ratio such that the trade is VIX-neutral. Maintenance of the strategy requires monthly rebalancing and would incur estimated transaction costs of $0.01 \%$ per day based on a typical bid-ask spread of 0.05 on the underlying VIX futures price. $\neq$ The return figures themselves,

$\dagger$ See Chapters 30-33 in Schwager (1984) for background. Also, Szymanowska et al. (2014) implement this strategy in their analysis of futures risk premia.

\$ Assuming a VIX futures price of 22 (see table 1, panel 1), investor incurs bid-ask spread transaction costs of 0.05 on 22.00 , or $0.23 \%$, as reported, do not include the estimated transaction costs of $0.01 \%$ per day as the focus of this exercise is the relative returns among strategies, and the evolution of returns across time.

\subsection{VIX futures betas}

Futures contracts are assets that have some sensitivity, or beta hereafter, to the underlying asset. When futures are written on assets that trade free of restriction and with ample liquidity, no-arbitrage formulas govern the relationship between spot and futures prices, and this beta is relatively stable across tenors. $\S$ On the other hand, when the trading of assets is restricted in some way, such as the VIX which is cumbersome to replicate directly, convenience-yield pricing determines the spot-futures relationship and as a result the beta may vary greatly with tenor.II Table 4 contains the constantmaturity VIX futures betas with respect to the VIX index. Daily log returns for each constant-maturity futures contract are regressed on daily log changes in the VIX index, $R_{t}^{\mathcal{F}^{j}}=$ $\alpha+\beta R_{t}^{\mathrm{VIX}}+\varepsilon_{t}$, where $R_{t}^{X}=\ln \left(X_{t}\right)-\ln \left(X_{t-1}\right)$ for $X$ prices.

Short maturity futures have materially higher betas to the VIX than do long maturity ones, and the variation across tenors is large. The near-term or 1st future has a beta of 0.60 , while the 8-month futures beta drops off significantly at only 0.16. For comparison purposes, I report betas for constantmaturity EUR/USD exchange rate forward contracts to the EUR/USD spot rate. The spot rate measures the number of dollars required for each euro. Although betas diverge from 1.0 with tenor, as they do for VIX futures, the variation is very small between 1 and 8-month tenors as a result of no-arbitrage pricing dynamics.

This phenomenon is at the core of why short-maturity contracts are most often used in the creation and management of VIX ETN's. Figure 5 tracks the market capitalization of the largest and most widely-held VIX ETN's, broken down by those that use short-term futures versus those that use long-term futures in their construction.

The VXX ETN, the largest by market capitalization, offers exposure to the short-end of the term structure and thus a risk profile that most closely mimics that of the underlying VIX index. The XVZETN, in contrast, offers exposure to the entire term structure depending on perceived value at the discretion of the money manager. Investors seek exposure to the VIX index, and shorter-maturity contracts in being more tightlylinked to the target asset, are more often-used versus longermaturity contracts.

\subsection{Exposure-neutral spread trades}

The strategy, EN, maintains a long constant-maturity VIX futures position for a long-maturity tenor $L$ and, simultaneously, a short constant-maturity futures position for

when rebalancing the trade each month. Since the typical month has 21 trading days, this amounts to approximately $0.01 \%$ in costs per day.

$\S$ Examples: S\&P 500 index, EUR/USD exchange rate, gold. II Consumption commodities such as oil and orange juice would also fall in this category, as would bitcoin. 
Table 4. Constant-maturity VIX futures betas (Jan 2006-Dec 2018).

\begin{tabular}{|c|c|c|c|c|c|c|c|c|}
\hline \multicolumn{9}{|c|}{ Constant-maturity VIX future betas to VIX (\%) } \\
\hline & $\mathcal{F}^{1}$ & $\mathcal{F}^{2}$ & $\mathcal{F}^{3}$ & $\mathcal{F}^{4}$ & $\mathcal{F}^{5}$ & $\mathcal{F}^{6}$ & $\mathcal{F}^{7}$ & $\mathcal{F}^{8}$ \\
\hline$\beta$ & 60 & 41 & 33 & 27 & 22 & 20 & 19 & 16 \\
\hline \multicolumn{9}{|c|}{ Constant-maturity EUR/USD forward betas to EUR/USD spot (\%) } \\
\hline & $f^{1}$ & $f^{2}$ & $f^{3}$ & $f^{4}$ & $f^{5}$ & $f^{6}$ & $f^{7}$ & $f^{8}$ \\
\hline$\beta$ & 99.9 & 99.8 & 99.6 & 99.4 & 99.2 & 99.0 & 98.8 & 98.6 \\
\hline
\end{tabular}

Note: This table contains the constant-maturity VIX futures betas with respect to the VIX index. Daily log returns for each constant-maturity futures contract are regressed on daily log returns for the VIX index according to $R_{t}^{\mathcal{F}^{j}}=$ $\alpha+\beta R_{t}^{\mathrm{VIX}}+\varepsilon_{t}$, where $R_{t}^{X}=\ln \left(X_{t}\right)-\ln \left(X_{t-1}\right)$ for $X$ prices.

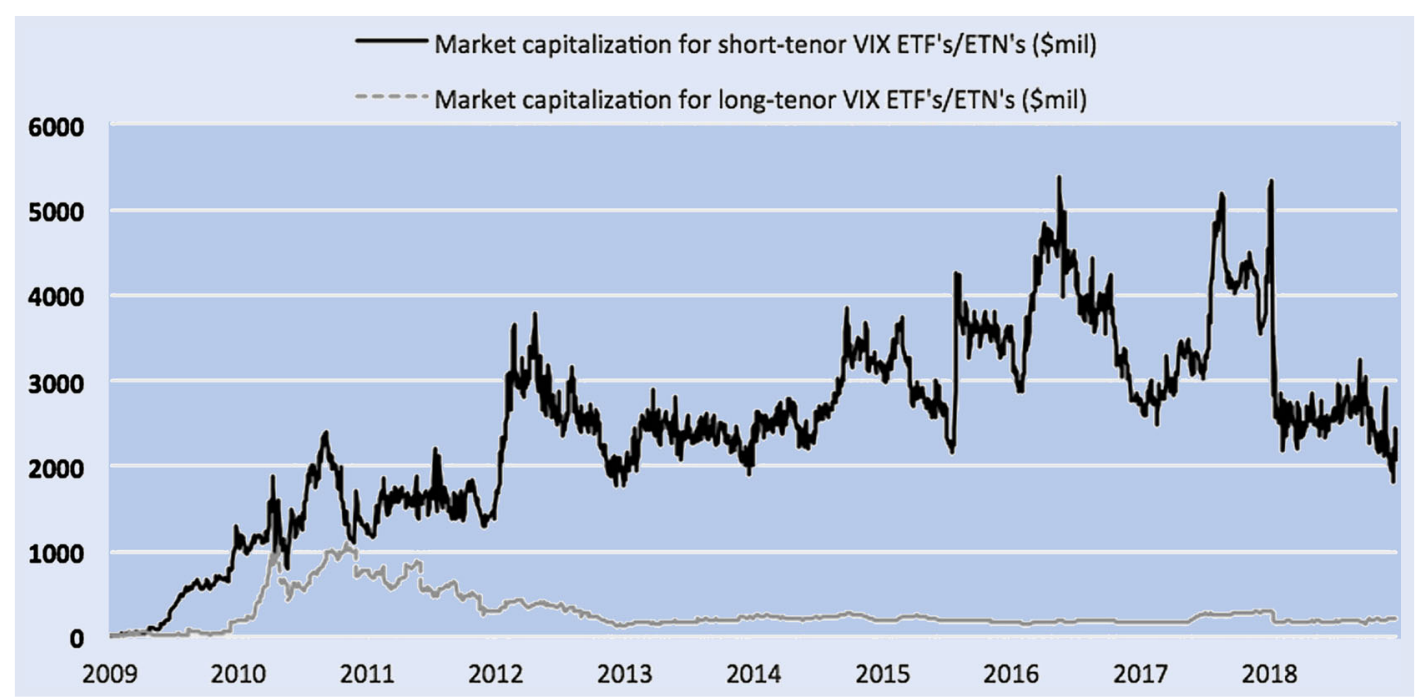

Figure 5. Market capitalization of short-tenor versus long-tenor VIX ETN's.

This figure tracks the market capitalization of the largest and most widely-held VIX ETN's that use short-term futures versus those that use long-term futures, per table 4 in Eraker and $\mathrm{Wu}$ (2017). Short-maturity contracts are most often used in the creation and management of VIX ETN's as they have materially higher betas to the VIX than do long maturity ones. Investors seek exposure to the VIX index, and shorter-maturity contracts are more tightly-linked to the target asset.

a short-maturity tenor $S$ in equal units of capital. The daily payoff for $E N_{L, S}$ is $\frac{1}{2} R_{t}^{L}-\frac{1}{2} R_{t}^{S}$ for each unit of capital. I report performance statistics in table 5 for 16 distinct $L-S$ spread trade combinations. For comparison purposes, I also report the performance of shorting the short-maturity legs only.

Estimated transaction costs are $0.01 \%$ per day, thus all but 2 of the 16 exposure-neutral spread combinations $\left(E N_{6,4}\right.$, $\left.E N_{5,4}\right)$ generated returns above transaction costs. Although the spread returns are lower than selling the higher beta shortmaturity legs by themselves, the annualized Sharpe ratios are materially better for the spreads, as is the downside risk profile as described by the worst day and largest drawdown statistics for a majority of the combinations. Largest drawdown is the percentage loss between the peak and the subsequent trough. By construction, exposure-neutral spreads constitute net selling of volatility, as the short-maturity leg carries a higher beta. The excess returns are then, in part, compensation for selling insurance.

\subsection{Beta-neutral spread trades}

Next, I evaluate spreads which neutralize the exposure to the VIX. Excess returns, if any, will be attributable to something other than volatility risk compensation. The strategy, $B N$, maintains a long constant-maturity VIX futures position for a long-maturity tenor $L$ and, simultaneously, a short constant-maturity VIX futures position for a shortmaturity tenor $S$ in amounts such that the net position is VIX-neutral. The daily payoff for $B N_{L, S}$ is $w_{L} R_{t}^{L}-w_{S} R_{t}^{S}$, where $w_{L}=\left(1 / \beta_{L}\right) /\left[\left(1 / \beta_{L}\right)+\left(1 / \beta_{S}\right)\right]$ and $w_{S}=1-w_{L}$ represent the weights for the long and short positions respectively for each unit of capital, and the $\beta^{\prime} s$ represent the constantmaturity betas from table 4 . I report performance statistics in table 6 for 16 distinct $L-S$ spread trade combinations, as well as the performance of shorting the short-maturity legs only.

The beta-neutral strategy generates excess returns, above transaction costs, primarily for combinations involving the 7 and 8-month tenors for the long-maturity leg, and the 1 and 2-month tenors for the short-maturity leg (in total 9 of 16 spread combinations). For this profitable subset, the Sharpe ratios are comparable to those of simply selling volatility naked, with much improved asymmetric risk profiles. This beta-neutral strategy is structurally different than a typical volatility-writing strategy. The aim in the beta-neutral strategy is to exploit futures pricing anomalies highlighted by violations of the expectations hypothesis reported: (1) forecast bias 
Table 5. Constant-maturity VIX futures spread returns (Jan 2006-Dec 2018).

\begin{tabular}{|c|c|c|c|c|c|c|}
\hline \multicolumn{7}{|c|}{ Exposure-neutral spread returns (\%) } \\
\hline & Average & Std dev & Worst day & Geometric annual & Sharpe & Drawdown \\
\hline$E N_{8,1}$ & 0.14 & 1.99 & -32.4 & 27.3 & 83 & -44 \\
\hline$E N_{7,1}$ & 0.11 & 1.78 & -19.6 & 22.4 & 77 & -35 \\
\hline$E N_{6,1}$ & 0.10 & 1.79 & -26.6 & 20.6 & 70 & -38 \\
\hline$E N_{5,1}$ & 0.09 & 1.73 & -30.9 & 18.9 & 66 & -41 \\
\hline$-\mathcal{F}^{1}$ & 0.27 & 4.94 & -75.4 & 40.9 & 47 & -84 \\
\hline$E N_{8,2}$ & 0.11 & 1.27 & -26.0 & 22.2 & 106 & -33 \\
\hline$E N_{7,2}$ & 0.07 & 1.06 & -13.2 & 16.6 & 96 & -6 \\
\hline$E N_{6,2}$ & 0.06 & 1.06 & -20.2 & 14.0 & 81 & -6 \\
\hline$E N_{5,2}$ & 0.05 & 1.01 & -24.5 & 12.4 & 75 & -5 \\
\hline$-\mathcal{F}^{2}$ & 0.19 & 3.54 & -62.5 & 34.8 & 57 & -70 \\
\hline$E N_{8,3}$ & 0.07 & 0.98 & -25.5 & 14.4 & 88 & -30 \\
\hline$E N_{7,3}$ & 0.04 & 0.73 & -12.6 & 8.53 & 72 & -5 \\
\hline$E N_{6,3}$ & 0.02 & 0.76 & -19.7 & 5.76 & 46 & -23 \\
\hline$E N_{5,3}$ & 0.02 & 0.75 & -24.0 & 4.60 & 37 & -27 \\
\hline$-\mathcal{F}^{3}$ & 0.12 & 2.94 & -61.4 & 19.7 & 38 & -67 \\
\hline$E N_{8,4}$ & 0.05 & 0.72 & -17.5 & 9.00 & 76 & -21 \\
\hline$E N_{7,4}$ & 0.02 & 0.51 & -4.72 & 4.94 & 60 & -4 \\
\hline$E N_{6,4}$ & 0.00 & 0.51 & -11.8 & 2.33 & 28 & -3 \\
\hline$E N_{5,4}$ & 0.00 & 0.50 & -16.0 & 0.76 & 9 & -17 \\
\hline$-\mathcal{F}^{4}$ & 0.09 & 2.46 & -45.6 & 14.4 & 35 & -52 \\
\hline
\end{tabular}

Note: This table includes performance for strategy, $E N$, that maintains a long constant-maturity VIX futures position for a long-maturity tenor $L$ and, simultaneously, a short constant-maturity futures position for a short-maturity tenor $S$ in equal units of capital. The daily payoff for $E N_{L, S}$ is $\frac{1}{2} R_{t}^{L}-\frac{1}{2} R_{t}^{S}$ for each unit of capital. I report performance statistics in table 5 for 16 distinct $L-S$ spread trade combinations. Standard deviation and worst days are reported for daily returns. Geometric average annual figures and Sharpe ratios are based on daily log returns. Largest drawdown is the percentage loss between the peak and the subsequent trough. Estimated transaction costs (not included in the results) are $0.01 \%$ per day, thus all but 2 of the 16 exposure-neutral spread combinations $\left(E N_{6,4}, E N_{5,4}\right)$ generated returns above transaction costs.

Table 6. Constant-maturity VIX futures spread returns (Jan 2006-Dec 2018).

Beta-neutral spread returns (\%)

\begin{tabular}{|c|c|c|c|c|c|c|}
\hline & Average & Std dev & Worst day & Geometric annual & Sharpe & Drawdown \\
\hline$B N_{8,1}$ & 0.04 & 0.90 & -8.00 & 7.65 & 53 & -29 \\
\hline$B N_{7,1}$ & 0.02 & 0.86 & -9.43 & 4.50 & 33 & -31 \\
\hline$B N_{6,1}$ & 0.02 & 0.80 & -4.53 & 3.07 & 24 & -42 \\
\hline$B N_{5,1}$ & 0.01 & 0.83 & -10.2 & 2.11 & 16 & -51 \\
\hline$-\mathcal{F}^{1}$ & 0.27 & 4.94 & -75.4 & 40.9 & 47 & -84 \\
\hline$B N_{8,2}$ & 0.05 & 0.75 & -10.2 & 9.17 & 76 & -22 \\
\hline$B N_{7,2}$ & 0.03 & 0.67 & -6.97 & 5.73 & 53 & -15 \\
\hline$B N_{6,2}$ & 0.02 & 0.62 & -5.44 & 3.86 & 38 & -19 \\
\hline$B N_{5,2}$ & 0.01 & 0.65 & -12.8 & 3.03 & 29 & -26 \\
\hline$-\mathcal{F}^{2}$ & 0.19 & 3.54 & -62.5 & 34.8 & 57 & -70 \\
\hline$B N_{8,3}$ & 0.04 & 0.71 & -13.6 & 7.12 & 53 & -19 \\
\hline$B N_{7,3}$ & 0.02 & 0.54 & -5.69 & 3.21 & 33 & -8 \\
\hline$B N_{6,3}$ & 0.005 & 0.55 & -9.64 & 0.82 & 9 & -17 \\
\hline$B N_{5,3}$ & 0.003 & 0.60 & -16.6 & 0.21 & 2 & -24 \\
\hline$-\mathcal{F}^{3}$ & 0.12 & 2.94 & -61.4 & 19.7 & 38 & -67 \\
\hline$B N_{8,4}$ & 0.03 & 0.60 & -10.7 & 5.07 & 76 & -14 \\
\hline$B N_{7,4}$ & 0.01 & 0.46 & -4.94 & 2.03 & 28 & -5 \\
\hline$B N_{6,4}$ & 0.001 & 0.43 & -6.73 & -0.16 & -2 & -15 \\
\hline$B N_{5,4}$ & 0.004 & 0.46 & -13.0 & -1.09 & -15 & -25 \\
\hline$-\mathcal{F}^{4}$ & 0.09 & 2.46 & -45.6 & 14.4 & 35 & -52 \\
\hline
\end{tabular}

Note: This table includes performance for the strategy, $B N$, that maintains a long constant-maturity VIX futures position for a long-maturity tenor $L$ and, simultaneously, a short constant-maturity futures position for a short-maturity tenor $S$ in amounts such that the net position is VIX-neutral. The daily payoff for $B N_{L, S}$ is $w_{L} R_{t}^{L}-w_{S} R_{t}^{S}$, where $w_{L}=\left(1 / \beta_{L}\right) /\left[\left(1 / \beta_{L}\right)+\left(1 / \beta_{S}\right)\right]$ and $w_{S}=1-w_{L}$ represent the weights for the long and short positions respectively for each unit of capital, for 16 distinct $L-S$ spread trade combinations. Standard deviation and worst days are reported for daily returns. Geometric average annual figures and Sharpe ratios are based on daily log returns. Largest drawdown is the percentage loss between the peak and the subsequent trough. Estimated transaction costs (not included in the results) are $0.01 \%$ per day, thus 9 of 16 strategies generated excess returns above transaction costs. 


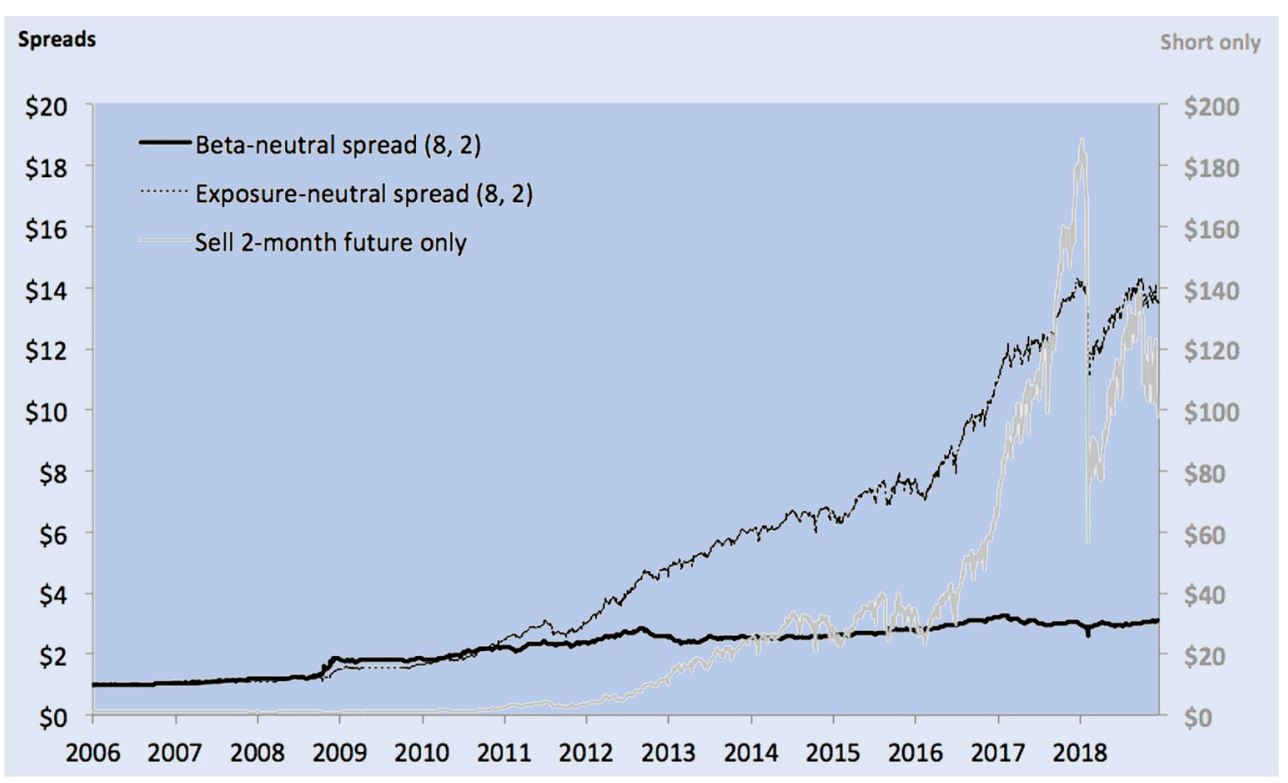

Figure 6. Evolution of spread trade profits.

This figure shows the evolution of spread trade profits for $\$ 1$ invested (aka the equity curve) in three different strategies: (1) $E N_{8,2}$, (2) $B N_{8,2}$ (left $y$-axis), and (3) maintaining a constant-maturity short position in the 2-month VIX futures only (right $y$-axis). Profits for the straight volatility-writing strategy accumulate quicker, however, they are subject to significant drawdowns during bouts of risk aversion and capital flight. In contrast, the spread trades monetize profits at a more modest pace, but are not as exposed to adverse tail events.

persists across the curve, and (2) the forecast bias is greater for short-maturity contracts versus long-maturity contracts. The agenda in a typical volatility-writing strategy is to earn premiums in excess of policy redemptions. The exposure-neutral strategy is a compromise between the two extremes, in other words, a hedged bet on being short volatility. Figure 6 shows the evolution of spread trade profits for $\$ 1$ invested (aka the equity curve) in three different strategies: (1) $E N_{8,2}$, (2) $B N_{8,2}$ (left $y$-axis), and (3) maintaining a constant-maturity short position in the 2-month VIX futures only (right $y$-axis).

Profits for the straight volatility-writing strategy accumulate quicker, however, they are subject to significant drawdowns during bouts of risk aversion and capital flight. In fact, the largest of these bouts came in February of 2018, when we saw drawdowns of $-70 \%$ for the 2-month futures volatility-writing strategy, and $-84 \%$ for the same strategy involving 1-month futures. Outright volatility strategies are generally characterized as 'picking up nickels and dimes in front of a steamroller'. The steamroller came, and in fact, led to the closing of one of the largest VIX ETN's which shorted the VIX via short-dated VIX futures (primarily 1 and 2 month tenors) as its building blocks. $\dagger$ The VelocityShares Daily Inverse VIX Short-Term exchange-traded note (ticker symbol XIV) generated impressive total returns from taking in insurance premiums over the bull run in stocks, only to see these most profits be wiped out in a sharp reversal. In contrast, the $B N$ spread trades monetize profits at a more modest pace, but are not as exposed to adverse tail events.

This section validates the availability of spread trade excess returns whose foundation is the expectations hypothesis deviations reported. For the exposure-neutral variety, 14 of 16 combinations are profitable and for the beta-neutral variety,

$\dagger$ For press coverage: https://www.cnbc.com/2018/02/06/theobscure-volatility-security-thats-become-the-focus-of-this-sell-offis-halted-after-an-80-percent-plunge.html
9 of 16 are profitable, above transaction costs. In the next section, I will regress trade profits, as in Matthias et al. (2013), on a number of factors as a way to understand what propagates the spread trade profits, and by extension, expectations hypothesis deviations.

\section{What drives the VIX futures term structure behavior?}

The time series of realized spread trade profits, proxy for the expectations hypothesis deviations in the VIX term structure, will serve as the independent variable in the set of OLS regressions.

\subsection{Relation to equity market factors}

First, I evaluate the extent to which profits arise as compensation from having exposure to equity downside risk. I regress trade profits for what would be considered the benchmark, selling constant-maturity VIX futures naked, onto the three Fama/French factors. $\$$ Table 7 contains the results from fitting $R_{t}^{\mathcal{F}^{j}}=a+b_{1} R M R F_{t}+b_{2} S M B_{t}+b_{3} H M L_{t}+\varepsilon_{t}$, where $R_{t}^{\mathcal{F}^{j}}$ are daily returns from selling constant-maturity VIX futures, $R M R F$ measures market returns over the riskfree rate, $S M B$ measures excess returns of small caps over big caps, and $H M L$ measures excess returns of value stocks over growth stocks.

The Fama-French three-factor model explains roughly half of the variation in profits from shorting constant-maturity VIX futures. The most significant contribution comes from $R M R F$, not surprisingly, and there is a multiplier effect at work. One unit of market return translates into more than one unit of short volatility returns, which is validated due to the leverage

$\ddagger$ See Fama and French (1993). 
Table 7. Relation to equity market factors (Jan 2006-Dec 2018).

\begin{tabular}{lrrrrr}
\hline \multicolumn{7}{c}{ OLS for short constant-maturity VIX futures trades } \\
\hline \multicolumn{7}{c}{ RMRF } & SMB & $H M L$ & cons & adj $R^{2}$ \\
\hline $\mathcal{F}^{1}$ & 3.00 & 0.167 & -0.650 & 0.168 & 0.51 \\
& {$[55.3]$} & {$[1.55]$} & {$[-6.59]$} & {$[2.78]$} & \\
$-\mathcal{F}^{2}$ & 2.09 & 0.181 & -0.378 & 0.111 & 0.49 \\
& {$[52.6]$} & {$[2.29]$} & {$[-5.23]$} & {$[2.54]$} & \\
$-\mathcal{F}^{3}$ & 1.70 & 0.065 & -0.308 & 0.063 & 0.47 \\
& {$[50.1]$} & {$[0.95]$} & {$[-5.01]$} & {$[1.67]$} & \\
$-\mathcal{F}^{4}$ & 1.44 & 0.052 & -0.231 & 0.038 & 0.49 \\
& {$[50.1]$} & {$[0.94]$} & {$[-4.56]$} & {$[1.21]$} & \\
$-\mathcal{F}^{5}$ & 1.25 & 0.069 & -0.213 & 0.031 & 0.52 \\
& {$[54.2]$} & {$[1.50]$} & {$[-5.14]$} & {$[1.19]$} & \\
$-\mathcal{F}^{6}$ & 1.09 & 0.104 & -0.181 & 0.027 & 0.45 \\
& {$[46.5]$} & {$[2.21]$} & {$[-4.26]$} & {$[1.03]$} & \\
$-\mathcal{F}^{7}$ & 1.04 & -0.025 & -0.209 & 0.026 & 0.37 \\
& {$[38.7]$} & {$[-0.47]$} & {$[-4.36]$} & {$[1.03]$} & \\
$-\mathcal{F}^{8}$ & 0.963 & -0.019 & -0.166 & -0.012 & 0.39 \\
& {$[37.7]$} & {$[-3.79]$} & {$[-3.64]$} & {$[-0.43]$} & \\
\hline
\end{tabular}

Note: This table contains OLS regression results where the dependent variables are the daily realized profits for maintaining short constant-maturity VIX futures position for tenors 1-8, regressed on the Fama-French equity market factors $R M R F$, $S M B$, and HML. RMRF measures market returns over the riskfree rate, $S M B$ measures excess returns of small caps over big caps, and $H M L$ measures excess returns of value stocks over growth stocks. OLS $t$-statistics are reported in square brackets below the coefficient estimates. $R$-squared readings are also reported.

feature of options. The small versus large factor has positive loadings, although not generally significant. The value factor has a negative significant loadings, a result explained by the fact that value stocks generally outperform during risk off periods, which would dampen volatility-writing strategy profits.

Table 8, panel 1, contains the results from fitting $R_{t}^{E N_{L, S}}=$ $a+b_{1} R M R F_{t}+b_{2} S M B_{t}+b_{3} H M L_{t}+\varepsilon_{t}$ for the top 8 bestperforming exposure-neutral spread trade combinations on the Fama-French equity market factors.

The $R$-squared readings are about 0.10 lower on average for the exposure-neutral versus the naked volatility-writing strategy, although still material, ranging from 0.26 to 0.46 . The contribution from $R M R F$ is strong and significant, although no longer leveraged as this is a partially-hedged bet on shorting volatility. The value factor is also significant and its negative loading can be attributed to the fact that the return potential of value stocks decreases the longer the equity bull cycle lasts. In contrast, stock sell-offs often lead to a rotation into value stocks, hence the negative association highlighted.

Table 8, panel 2, contains the results from fitting $R_{t}^{B N_{L, S}}=$ $a+b_{1} R M R F_{t}+b_{2} S M B_{t}+b_{3} H M L_{t}+\varepsilon_{t}$ for the top 8 bestperforming beta-neutral spread trade combinations on the Fama-French equity market factors. Without exception, the OLS fits are insignificant, confirming that profits from betaneutral spread trades evolve as a result of something other than compensation for selling insurance to protect against stock market losses.
Table 8. Relation to equity market factors (Jan 2006-Dec 2018).

\begin{tabular}{|c|c|c|c|c|c|}
\hline & $R M R F$ & $S M B$ & $H M L$ & cons & $\operatorname{adj} R^{2}$ \\
\hline \multicolumn{6}{|c|}{ Panel 1: OLS for exposure-neutral spread trades } \\
\hline \multirow[t]{2}{*}{$E N_{8,1}$} & 1.190 & 0.013 & -0.349 & 0.083 & 0.43 \\
\hline & [41.8] & {$[0.23]$} & {$[-6.84]$} & {$[2.80]$} & \\
\hline \multirow{2}{*}{$E N_{8,2}$} & 0.692 & 0.044 & -0.179 & 0.074 & 0.37 \\
\hline & [36.2] & [1.17] & {$[-5.22]$} & [3.71] & \\
\hline \multirow{2}{*}{$E N_{8,3}$} & 0.456 & 0.001 & -0.129 & 0.050 & 0.26 \\
\hline & [28.4] & {$[0.03]$} & {$[-4.49]$} & [2.97] & \\
\hline \multirow[t]{2}{*}{$E N_{7,1}$} & 1.040 & 0.006 & -0.273 & 0.077 & 0.46 \\
\hline & [46.3] & [0.14] & {$[-6.83]$} & [3.14] & \\
\hline \multirow[t]{2}{*}{$E N_{7,2}$} & 0.570 & 0.045 & -0.106 & 0.058 & 0.40 \\
\hline & [40.4] & {$[1.63]$} & {$[-4.20]$} & [3.75] & \\
\hline \multirow[t]{2}{*}{$E N_{7,3}$} & 0.361 & -0.005 & -0.064 & 0.029 & 0.33 \\
\hline & [35.2] & {$[-0.23]$} & {$[-3.52]$} & [2.58] & \\
\hline \multirow[t]{2}{*}{$E N_{6,1}$} & 0.975 & 0.031 & -0.225 & 0.064 & 0.42 \\
\hline & [44.3] & {$[0.71]$} & {$[-5.66]$} & {$[2.56]$} & \\
\hline \multirow[t]{2}{*}{$E N_{6,2}$} & 0.513 & 0.040 & -0.093 & 0.044 & 0.34 \\
\hline & [37.1] & [1.46] & {$[-3.71]$} & [2.82] & \\
\hline \multicolumn{6}{|c|}{ Panel 2: OLS for beta-neutral spread trades } \\
\hline \multirow[t]{2}{*}{$B N_{8,1}$} & -0.037 & 0.017 & -0.055 & 0.042 & 0.005 \\
\hline & {$[-2.16]$} & [0.50] & {$[-1.80]$} & [2.36] & \\
\hline \multirow[t]{2}{*}{$B N_{8,2}$} & -0.022 & 0.012 & -0.030 & 0.047 & 0.003 \\
\hline & {$[-1.57]$} & [0.44] & {$[-1.18]$} & [3.17] & \\
\hline \multirow[t]{2}{*}{$B N_{8,3}$} & -0.010 & 0.017 & -0.033 & 0.037 & 0.002 \\
\hline & {$[-0.76]$} & {$[0.50]$} & {$[-1.38]$} & [2.62] & \\
\hline \multirow[t]{2}{*}{$B N_{7,1}$} & -0.021 & 0.016 & -0.027 & 0.024 & 0.002 \\
\hline & {$[-1.44]$} & {$[0.56]$} & {$[-1.04]$} & [1.51] & \\
\hline \multirow[t]{2}{*}{$B N_{7,2}$} & -0.011 & 0.037 & 0.007 & 0.027 & 0.001 \\
\hline & {$[-0.94]$} & [1.68] & [0.37] & [2.19] & \\
\hline \multirow[t]{2}{*}{$B N_{7,3}$} & 0.007 & 0.004 & 0.003 & 0.015 & 0.0004 \\
\hline & [1.53] & {$[0.26]$} & [0.18] & [1.53] & \\
\hline \multirow[t]{2}{*}{$B N_{6,1}$} & -0.058 & -0.036 & -0.022 & 0.018 & 0.011 \\
\hline & {$[-4.51]$} & {$[-1.40]$} & {$[-0.95]$} & [1.24] & \\
\hline \multirow[t]{2}{*}{$B N_{6,2}$} & -0.046 & -0.010 & 0.003 & 0.020 & 0.008 \\
\hline & {$[-4.60]$} & {$[-0.50]$} & {$[0.16]$} & [1.72] & \\
\hline
\end{tabular}

Note: This table, panel 1, contains OLS regression results for daily spread trade profits for the top 8 best-performing exposureneutral spread trade combinations on the Fama-French equity market factors $R M R F, S M B$, and HML. RMRF measures market returns over the risk-free rate, $S M B$ measures excess returns of small caps over big caps, and $H M L$ measures excess returns of value stocks over growth stocks. Panel 2 contains OLS regression results for spread trade profits for the respective beta-neutral combinations. OLS $t$-statistics are reported in square brackets below the coefficient estimates. $R$-squared readings are also reported.

\subsection{Relation to other factors for beta-neutral strategy}

The results of the previous section highlight an important distinction between the exposure-neutral and the beta-neutral spread trades. Profits for the exposure-neutral variety manifest, at least in part, due to compensation received for selling insurance. Among the best-performing combinations tested, equity market factors explain as much as $46 \%$ of the variation in profits from the $E N$ systematic strategy. On the other hand, equity market factors do not explain profits for the $B N$ relative value trades, by construction. Profits arise as a result of anomalies discovered in tests of the expectations hypothesis, namely that the degree of overshooting, between VIX futures prices ex ante and the evolution of the VIX index ex post, is persistent and rises with tenor. Profits for the beta-neutral 
Table 9. Correlation and unit root tests on the transformed dependent variables (Jan 2006-Dec 2018).

\begin{tabular}{|c|c|c|c|c|c|c|c|c|}
\hline Variable & LOI & NOI & HRV & G & $\mathrm{CT}$ & OIS & TVX & Dickey-Fuller $t$-statistic \\
\hline Long open interest (OI-L) & 1.00 & & & & & & & $-24.4^{*}$ \\
\hline Net open interest (OI-N) & 0.35 & 1.00 & & & & & & $-33.7^{*}$ \\
\hline HFRXRVA Index (HRV) & 0.20 & 0.00 & 1.00 & & & & & $-17.1^{*}$ \\
\hline Gold (G) & -0.06 & -0.06 & -0.04 & 1.00 & & & & $-23.8^{*}$ \\
\hline Carry-trade index (CT) & 0.07 & -0.09 & 0.36 & 0.34 & 1.00 & & & $-23.4^{*}$ \\
\hline Libor-OIS spread (OIS) & -0.06 & 0.06 & -0.24 & 0.10 & -0.07 & 1.00 & & $-18.3^{*}$ \\
\hline Treasury bond volatility (TVX) & -0.04 & 0.06 & -0.22 & -0.06 & -0.28 & 0.05 & 1.00 & $-28.3^{*}$ \\
\hline Momentum $\left(R_{t-1}^{B N_{8,1}}\right)$ & -0.13 & -0.07 & -0.09 & 0.03 & 0.08 & -0.04 & 0.05 & $-20.0^{*}$ \\
\hline Momentum $\left(R_{t-1}^{B N_{8,2}}\right)$ & -0.21 & -0.08 & -0.13 & 0.03 & 0.06 & 0.04 & 0.06 & $-20.7^{*}$ \\
\hline Momentum $\left(R_{t-1}^{B N_{8,3}}\right)$ & -0.22 & -0.08 & -0.17 & 0.05 & 0.06 & 0.04 & 0.07 & $-20.2^{*}$ \\
\hline $\operatorname{Momentum}\left(R_{t-1}^{B N_{7,1}}\right)$ & -0.14 & -0.06 & -0.06 & 0.01 & 0.08 & -0.05 & 0.04 & $-21.9^{*}$ \\
\hline Momentum $\left(R_{t-1}^{B N_{7,2}}\right)$ & -0.21 & -0.08 & -0.04 & 0.01 & 0.08 & 0.00 & 0.03 & $-22.6^{*}$ \\
\hline Momentum $\left(R_{t-1}^{B N_{7,3}}\right)$ & -0.19 & -0.04 & -0.05 & 0.02 & 0.07 & 0.02 & 0.04 & $-22.6^{*}$ \\
\hline $\operatorname{Momentum}\left(R_{t-1}^{B N_{6,1}}\right)$ & -0.03 & -0.03 & -0.06 & 0.00 & 0.06 & -0.06 & 0.04 & $-22.4^{*}$ \\
\hline Momentum $\left(R_{t-1}^{B N_{6,2}}\right)$ & -0.09 & -0.04 & -0.05 & 0.02 & 0.06 & 0.01 & 0.03 & $-23.8^{*}$ \\
\hline
\end{tabular}

Note: ${ }^{*}$ Indicates rejections at $1 \%$ level of null hypothesis that a unit root is present.

This table contains a correlation matrix and unit root tests on the transformed variables for non-overlapping weekly data $(N=542)$.

Table 10. Relation to other factors for beta-neutral strategy (Jan 2006-Dec 2018).

OLS involving beta-neutral spread trades

\begin{tabular}{lcccccrrr}
\hline & \multicolumn{7}{c}{ Coefficients } \\
\cline { 2 - 9 } Transformed variables & $B N_{8,1}$ & $B N_{8,2}$ & $B N_{8,3}$ & $B N_{7,1}$ & $B N_{7,2}$ & $B N_{7,3}$ & $B N_{6,1}$ & $B N_{6,2}$ \\
\hline Long open interest & $0.026^{*}$ & $0.021^{*}$ & $0.015^{*}$ & $0.015^{*}$ & 0.008 & 0.006 & 0.012 & 0.009 \\
Net open interest & -0.005 & -0.001 & -0.002 & -0.022 & -0.018 & -0.018 & 0.002 & -0.006 \\
HFRXRVA Index & $-0.382^{*}$ & $-0.390^{*}$ & $-0.372^{*}$ & -0.031 & -0.051 & -0.006 & -0.050 & -0.077 \\
Gold & -0.008 & -0.019 & -0.019 & -0.011 & -0.023 & -0.015 & 0.027 & 0.013 \\
Carry-trade index & -0.125 & -0.058 & -0.049 & $-0.189^{*}$ & $-0.087^{*}$ & $-0.073^{*}$ & $-0.198^{*}$ & $-0.094^{*}$ \\
Libor-OIS spread & -0.006 & 0.001 & 0.003 & -0.005 & 0.003 & 0.005 & $-0.013^{*}$ & -0.002 \\
Treasury bond volatility & -0.006 & -0.002 & -0.002 & -0.015 & -0.007 & -0.004 & -0.009 & -0.001 \\
Momentum & $0.164^{*}$ & $0.135^{*}$ & $0.142^{*}$ & $0.123^{*}$ & $0.087^{*}$ & $0.086^{*}$ & $0.113^{*}$ & 0.056 \\
Constant & $0.160^{*}$ & $0.186^{*}$ & $0.141^{*}$ & 0.116 & $0.140^{*}$ & $0.079^{*}$ & 0.077 & 0.073 \\
$F$ & $5.08^{*}$ & $5.88^{*}$ & $7.20^{*}$ & $8.26^{*}$ & $3.26^{*}$ & $2.35^{*}$ & $3.64^{*}$ & 1.80 \\
Adjusted R-squared & 0.06 & 0.07 & 0.08 & 0.10 & 0.03 & 0.02 & 0.03 & 0.01 \\
\hline
\end{tabular}

Note: *Indicates significance at the $5 \%$ level.

Profits for the beta-neutral spread strategy will serve as proxy for the magnitude of the bias reported in the expectations hypothesis tests: futures prices are systematically higher than ex post VIX realizations and such biases narrow with tenor. I regress changes in trade profits against changes in a number of factors. These factors are VIX futures open interest (for both long and net positions), the HFRXRVA Index (a measure of total hedge fund net asset values for portfolios that engage in relative value strategies, from Hedge Fund Research Inc.), gold prices (safe-haven asset), carry trade performance (Bloomberg ticker FXCTEM8 tracking the performance of a portfolio of high-yielding currencies from the perspective of a US investor), Libor-OIS spread (measures credit stress level in financial markets), TYVIX (the analogue of the VIX for the US treasury bond market), and momentum (the previous week's spread trade return).

strategy, then, are the most direct proxy for examining the persistence of this expectations hypothesis deviations.

To that end, I regress changes in trade profits against changes in a number of factors. These factors are VIX futures open interest (for both long and net positions), the HFRXRVA Index (a measure of total hedge fund net asset values for portfolios that engage in relative value strategies, from Hedge Fund Research Inc.), gold prices (safe-haven asset), carry trade performance (Bloomberg ticker FXCTEM8 tracking the performance of a portfolio of high-yielding currencies from the perspective of a US investor), Libor-OIS spread (measures credit stress level in financial markets), TYVIX (the analogue of the VIX for the US treasury bond market), and momentum (the previous week's spread trade return). The frequency of the data for this regression is non-overlapping weekly, as opposed to daily, as the VIX futures open interest data is available only on a weekly basis. Table 9 lists out the independent variables, reports the correlation among the transformed variables (weekly log changes), and carries out unit root tests on the transformed variables.

Correlation readings do not highlight potential problems that may arise from the existence of multicollinearity. Also, without exception, the transformed variables are stationary per the Dickey-Fuller tests. Table 10 contains results from fitting $R_{t}^{B N_{L, S}}=a+b_{1} L O I_{t}+b_{2} N_{O} I_{t}+$ $b_{3} H R V_{t}+b_{4} G_{t}+b_{5} C T_{t}+b_{6} \mathrm{OIS}_{t}+b_{7} T V X_{t}+b_{8} R_{t-1}^{B N_{L, S}}+\varepsilon_{t}$ for the top half best-performing beta-neutral spread trade combinations for the entire period (2006-2018). 
Table 11. Relation to other factors for beta-neutral strategy (VIX ETN period: Jan 2011-Dec 2018).

OLS involving beta-neutral spread trades

\begin{tabular}{lcccccccrc}
\hline & \multicolumn{7}{c}{ Coefficients } \\
\cline { 2 - 9 } Transformed variables & $B N_{8,1}$ & $B N_{8,2}$ & $B N_{8,3}$ & $B N_{7,1}$ & $B N_{7,2}$ & $B N_{7,3}$ & $B N_{6,1}$ & $B N_{6,2}$ \\
\hline Long open interest & $0.029^{*}$ & $0.017^{*}$ & 0.009 & $0.030^{*}$ & $0.018^{*}$ & $0.010^{*}$ & $0.033^{*}$ & $0.020^{*}$ \\
Net open interest & 0.094 & 0.001 & -0.022 & 0.072 & -0.042 & $-0.075^{*}$ & $0.157^{*}$ & 0.033 \\
HFRXRVA Index & $-0.423^{*}$ & $-0.400^{*}$ & $-0.287^{*}$ & -0.284 & $-0.265^{*}$ & -0.134 & $-0.410^{*}$ & $-0.379^{*}$ \\
Gold & 0.024 & -0.005 & 0.001 & 0.029 & -0.006 & -0.003 & 0.045 & 0.008 \\
Carry-trade index & $-0.194^{*}$ & -0.079 & -0.061 & $-0.153^{*}$ & -0.026 & -0.010 & $-0.191^{*}$ & -0.058 \\
Libor-OIS spread & $-0.022^{*}$ & -0.009 & -0.007 & $-0.023^{*}$ & -0.008 & -0.006 & -0.019 & -0.009 \\
Treasury bond volatility & -0.001 & -0.001 & -0.007 & -0.011 & -0.010 & -0.007 & -0.003 & -0.003 \\
Momentum & $0.150^{*}$ & $0.131^{*}$ & $0.116^{*}$ & $0.134^{*}$ & $0.098^{*}$ & 0.087 & $0.114^{*}$ & 0.090 \\
Constant & 0.006 & 0.088 & 0.081 & 0.005 & 0.094 & $0.076^{*}$ & -0.069 & 0.028 \\
$F$ & $4.82^{*}$ & $2.94^{*}$ & $2.31^{*}$ & $3.87^{*}$ & $1.80^{*}$ & $1.60^{*}$ & $4.70^{*}$ & $2.62^{*}$ \\
Adjusted R-squared & 0.07 & 0.04 & 0.03 & 0.05 & 0.02 & 0.01 & 0.07 & 0.03 \\
\hline
\end{tabular}

Note: ${ }^{*}$ Indicates significance at the $5 \%$ level.

Profits for the beta-neutral spread strategy will serve as proxy for the magnitude of the bias reported in the expectations hypothesis tests: futures prices are systematically higher than ex post VIX realizations and such biases narrow with tenor. I regress changes in trade profits against changes in a number of factors for the sub-period of 2011-2018, a period characterized by the proliferation of VIX ETN offerings. These factors are VIX futures open interest (for both long and net positions), the HFRXRVA Index (a measure of total hedge fund net asset values for portfolios that engage in relative value strategies, from Hedge Fund Research Inc.), gold prices (safe-haven asset), carry trade performance (Bloomberg ticker FXCTEM8 tracking the performance of a portfolio of high-yielding currencies from the perspective of a US investor), Libor-OIS spread (measures credit stress level in financial markets), TYVIX (the analogue of the VIX for the US treasury bond market), and momentum (the previous week's spread trade return).

Significant coefficients are VIX open interest, the HFRXRVA Index, the carry trade index, and momentum. The average adjusted $r$-squared reading for all 8 strategies is 0.05 (range $0.01-0.10$ ), notably higher than the regressions involving the Fama-French factors. The $F$-tests confirm the statistical significance of the regressions, although the intercept term is also significant for most combinations, suggesting the explanatory power is in part attributable to factors not included. Next, I run the same regression for the sub-period associated with the proliferation of VIX ETN offerings (20112018), conjecturing that the availability of such investment vessels contributed to propagating the spread-trade profits and, by proxy, the EH deviations. Results are summarized in table 11.

Adjusted $r$-squared readings are in line with those from the regressions covering the entire period, and $F$-tests also confirm the statistical significance of the linear relationships. However, there is greater stability regarding the significance of the coefficients across spread-trade combinations. For example, the open interest was significant in 4 of 8 combinations for 2006-2018, but significant in 7 of 8 combinations for the VIX ETN sub-period. In addition, the intercept term is only significant in one of the combinations, suggesting a better fit for this sub-period. Next I will discuss the intuition behind the most important factors, and summarize key elements learned from this exercise.

8.2.1. VIX futures open interest. In all but one of the spread-trade combinations, the coefficients for the VIX futures open interest are positive and significant at the 5\% level. Open interest appropriately measures the size of the VIX futures market, $\dagger$ so the positive loading implies that

$\dagger$ It is important to note that changes in open interest is a more direct measure of the flow of funds for VIX ETN's than the market capitalization data of the ETN's. Market capitalization may increase when the availability of profits rises with the size of the market. To understand the intuition for this result, it is important to formalize the link between open interest and VIX ETN's. The Global Financial Crisis of 2008 brought the VIX index to the financial mainstream spotlight, creating demand for owning the VIX as an asset that would pay off in bad times. Replicating the VIX directly, however is cumbersome, even for sophisticated professional investors. Along similar lines, managing a portfolio of futures and options written on the VIX index is not feasible for individual investors, family offices, and smaller professional funds. The investment management industry responded by offering VIX ETN's.

The transmission mechanism from ETN's to VIX futures markets is as follows. In order to provide individual investors with a risk profile that tracks the underlying VIX index, purveyors of the ETN's must trade futures and, to a lesser degree, options on the VIX.\$Figure 7 tracks the historical relationship between total VIX futures open interest and the market capitalization of the largest and most widely-held VIX ETN's, de facto validation of the impact of ETF proliferation on the VIX futures markets.

Prior to 2009, open interest averaged approximately 100000 contracts, topping out at just under 200000 . Then, the first VIX fund was introduced in January 2009, and by the end of 2010, there was over $\$ 3$ billion in VIX ETN market capitalization. The rapid growth in VIX open interest coincided with this proliferation of VIX ETN's. Furthermore, deeper

investment performance is positive, or when new money enters the strategy. Similarly, it is reduced by negative investment performance, as well as redemptions or withdrawals, including fund closures and client defections. Thus, changes in investment performance have the potential to influence market capitalization, such that the true flow of funds is best captured by futures open interest.

$\$$ Alexander and Korovilas (2012) describe this in greater detail. Also for an example of the construction of VIX ETN's, refer to https://www.sec.gov/Archives/edgar/data/312070/00011931251211 8832/d317408d424b3.htm. 


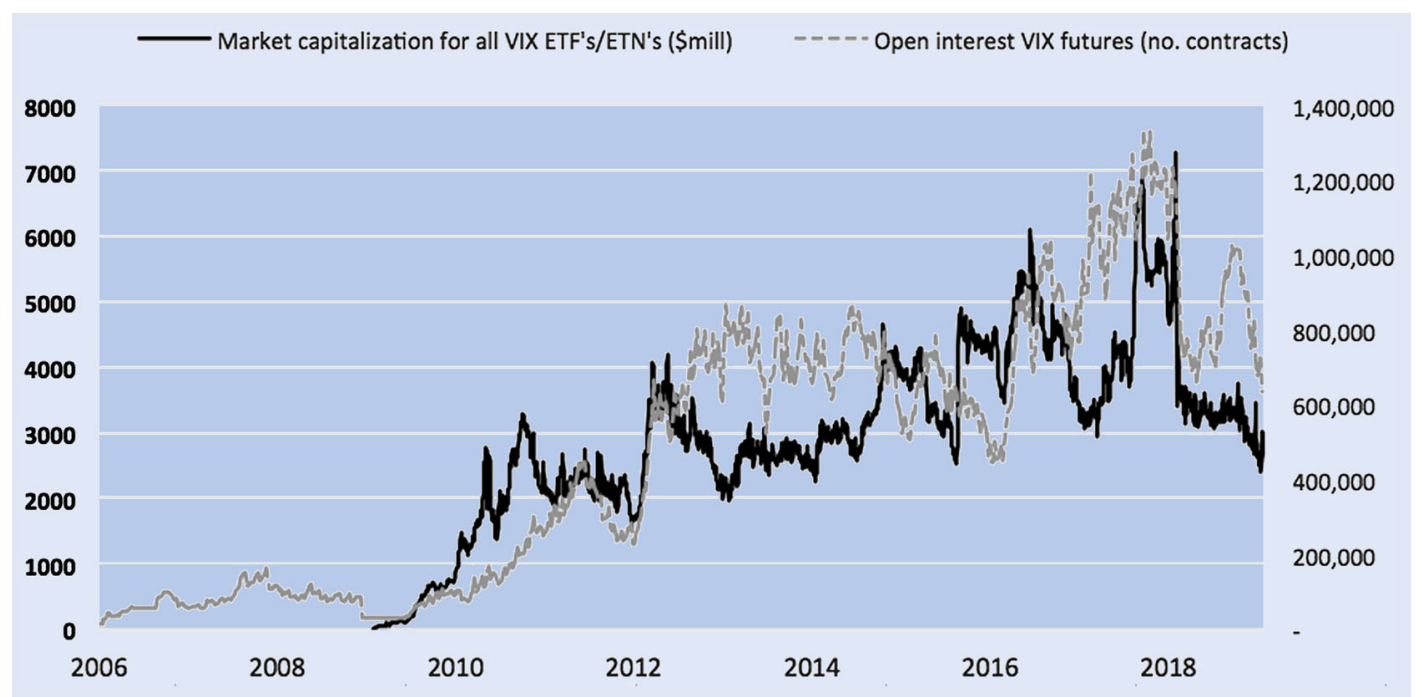

Figure 7. Market capitalization of the largest and most widely held VIX ETN's versus open interest in VIX futures.

This figure tracks the historical relationship between total VIX futures open interest and the market capitalization of the largest and most widely-held VIX ETN's, de facto validation of the impact of ETF proliferation on VIX futures markets. Prior to 2009, open interest averaged approximately 100000 contracts, topping out at just under 200000 . The first VIX fund was introduced in January 2009, and by the end of 2010 , there was over $\$ 3$ billion in VIX ETN market capitalization. The rapid growth in VIX open interest coincided with the proliferation of VIX ETN's.

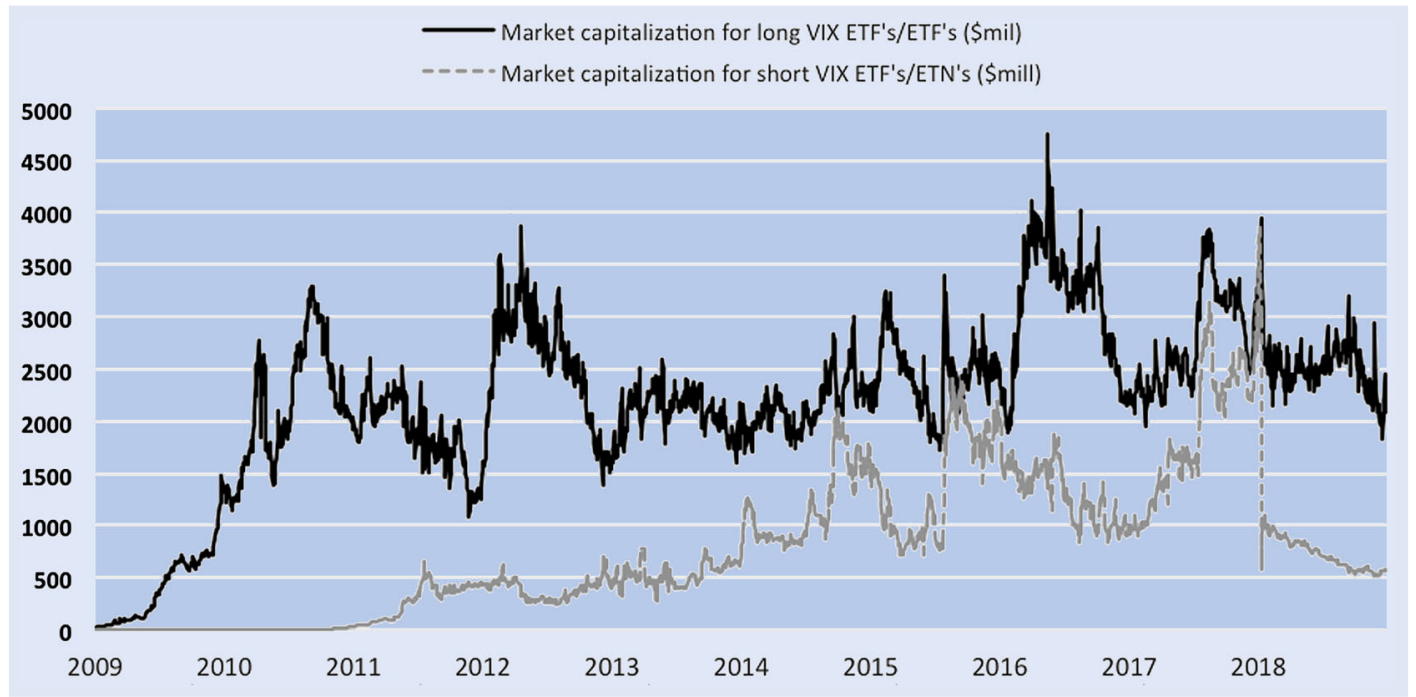

Figure 8. Market capitalization of long VIX ETN's versus short VIX ETN's.

ETF holdings betting for a rise in volatility have been consistently greater than ETF holdings betting on a fall in the index, resulting in stronger buying pressure versus selling pressure for VIX futures. This supports the disproportionally elevated level of the basis, and by extension, the term structure anomalies highlighted by the EH tests in this paper.

inspection reveals that the ETN demand was unbalanced. The market capitalizations of ETN holdings betting for a rise in volatility (long VIX ETN's) have exceeded those of ETN holdings betting on a fall in the index (short VIX ETN's) throughout most of the period. Figure 8 illustrates.

Greater buying interest for long VIX ETN's, over short VIX ETN's, translates into excess buying pressure for VIX futures (the analogue would also hold, greater buying of short VIX ETN's would translate into excess selling pressure of futures). This dynamic supports the persistent elevated level of the basis, as convenience-yield pricing, as opposed to arbitragefree pricing, governs the relationship between VIX spot and futures prices (the basis). In other words, since the VIX is not available as a buy and hold asset (replication is not feasible), excess demand for long VIX exposure manifests itself in upward pressure on the basis.

Furthermore, this impact is greater for shorter-maturity futures versus longer-maturity futures. It was established in Section 7.1 that short-maturity contracts are most often used in the creation and management of VIX ETN's. Investors seek exposure to the VIX index, and shorter-maturity contracts are more tightly-linked, have a higher beta, to the target asset. Figure 5 confirms that the market-capitalizations for VIX ETN's that use short-maturity futures far exceeds the market capitalizations of those that use longer-dated futures. It is this elevated basis, more pronounced in the short-end of the VIX futures curve, which is at the heart of the betaneutral spread trade profits, and by extension, the anomalies 
in the VIX futures term structure reported in expectations hypothesis tests.

\subsubsection{Availability of capital for relative value strategies.} Finance theory thinks of relative value opportunities as being temporary mispricing episodes. The availability of hedge fund capital that could potentially be directed towards arbitrage strategies should over time become negatively associated to relative value profits. The negative coefficients for the HFRXRVA Index $\dagger$ regressor validates this dynamic. The coefficients are significant for all but one of the spread trade combinations.

8.2.3. Investor risk appetite. Carry trades perform well during risk-on environments and underperform during bouts of risk aversion. Bloomberg tracks the investment performance of a portfolio of high-yielding currencies from the perspective of a US investor. The ticker is FXCTEM8 Index. The coefficient for this independent variable is negative for all combinations, and significant for three combinations. The inverse relationship makes sense. As risk appetite improves and carry trades do well, interest in volatility-writing strategies intensifies, working towards correcting the anomalies propagated by strong persistent inflows into long VIX ETN's.

8.2.4. Momentum. Momentum is an important factor in explaining returns for many asset classes. A trader new to the business is told that 'buying low and selling high' is not necessarily the key to excess profits. Instead, the trader is encouraged to buy into a rally after it's been established, and exit before the last trader has left the room. Recent work by Gorton et al. (2013) and Asness et al. (2013) establish the importance of momentum as it applies to futures markets specifically. The retail investment community has also embraced the strategy. According to ETFdb.com, there are 39 different ETN offerings focused on momentum across a number of different asset classes with assets exceeding $\$ 10$ billion, as of August 2017.

In this study, I investigate the existence of momentum by including, in the OLS regression, an independent variable which is the return for the beta-neutral spread trade for the previous non-overlapping weekly period. The positive coefficient establishes momentum as an element that propagates the relative value profits, and confirms the persistence of the availability of excess returns.

\section{Closing comments}

In this paper, I evaluate the information content of VIX futures prices, the core method of attaining exposure to the VIX index, by carrying out tests of the expectations hypothesis. I

$\dagger$ Published by Hedge Fund Research, Inc., the HFRXRVA Index tracks the net-asset value managed by relative value investment managers who maintain positions in which the investment thesis is predicated on realization of a valuation discrepancy in the relationship between multiple securities. address two questions. When the VIX term structure is positively (negatively) sloped, does the short-end of the curve subsequently rise (fall) as much as predicted according to the linearity with respect to time? And, when the term structure is positive (negative), does the long-end of the curve rise (fall) ex post and does it do so by the magnitude predicted? The structure I use allows for testing EH along the curve for each tenor, as opposed to from inception-to-end for each tenor. This results in a stronger test of $\mathrm{EH}$ since it incorporates pathdependency of the index. This is one contribution to the VIX literature made by this paper.

The key findings are as follows: (1) Term structure is an accurate predictor of the direction of the ex post evolution of the short-end of the curve, however, (2) the term structure overshoots in its prediction of the ex post movement of the short-end of the curve, (3) with regard to movements of the long-end of the curve, the term structure fails to predict both direction and magnitude, and (4) the predictive power of the term structure, related to both the evolution of the short-end and ex post movements in the long end, worsens with shorter tenors. Based on this exercise, I construct relative-valueseeking spread trades designed to profit from the anomalies reported. Exposure-neutral spread trades deliver significant excess returns with annualized Sharpe ratios that are comparable or better than those of volatility-writing strategies offered by VIX ETN's. This is an illuminating result, and important food-for-thought for institutional investors managing VIX ETN's and mutual funds.

The second contribution, once the expectations hypothesis anomalies have been documented, is to shed light on persistence. I construct a set of spread trades which are beta-neutral, designed to profit from EH findings. Then, I identify a number of factors that might influence the size of the bias over time, these factors are regressed on realized profits. Key findings are as follows. Profits are inversely related to the availability of hedge fund capital in search of relative value, an intuitive result as relative value trading activity generally works to correct biases. Along similar lines, the spread-trade profits are also inversely related to carry trade profits. Persistence is established from the positive loading for the momentum variable. Finally, the sign and significance of VIX futures open interest give rise to an important result. Application of the theory of slow-moving capital, as suggested by Gromb and Vayanos (2002) and Brunnermeier and Pedersen (2009), stresses that slow-moving capital may play a key role in propagating mispricing in financial markets. However, the opposite is happening in this market. Greater open interest for VIX futures, essentially the building blocks of VIX ETN's, propagates arbitrage profits. Investors, baited by the potential for outsized rewards from spikes in the VIX, have continued to pour money into long VIX strategies despite mounting losses. $¥$ The excess buying interest, concentrated at the shortend of the curve has, has maintained the basis for short-dated futures elevated with respect to longer-dated futures. This persistent dynamic is at the heart of the beta-neutral spread trade

$\$$ A dollar invested in the VXX ETN (one of the largest) on its inception date of $1 / 29 / 2009$ would be worth less than a penny less than 6 years later, as of 12/30/2014. 
profits, and by extension, the anomalies in the VIX futures term structure reported in this paper.

Looking ahead, the proliferation of ETF's and ETN's has important implications for the underlying assets that are used to furnish investors the risk profile that is promised. If derivatives are used to build synthetic assets, or offer leveraged returns, inefficiencies and forecast biases may emerge. This is an important area of research. The results of this paper support Alexander and Korovilas (2012), who establish that VIXrelated ETN's have grown so large that the hedging needs of market-makers have disrupted the market for VIX futures such that the ETN market now 'leads' the VIX futures that they are supposed to track. Discovering and reporting on relative value opportunities lessens the likelihood and severity of potential disturbances.

\section{Acknowledgements}

I am grateful for invaluable comments and suggestions from Michael Hutchison, Joshua Aizenman, Carl Walsh, Chris Limnios, Jeffrey Pontiff, Eric Fischer, Vlad Sushko, Garrett Lee, Joe Chan, Ludwig Chincarini, Roger Peng, Julian Sebastian, anonymous referees, and conference/seminar participants from University of California, Santa Cruz, Louisiana State University, University of Victoria, University of San Francisco, HSBC, ABF, Bank of International Settlements, Cornerstone Research, Vega Economics, Google, Guggenheim Partners, Goldman Sachs. Research support from the Cota-Robles Foundation and the Sury Initiative for Global Finance and International Risk Management (SIGFIRM) is also gratefully acknowledged.

\section{Disclosure statement}

No potential conflict of interest was reported by the author.

\section{References}

Ait-Sahalia, Y., Karaman, M. and Mancini, L., The term structure of variance swaps, risk premia and the expectations hypothesis. Working Paper, Princeton University, NBER, Swiss Finance Institute, University of Zurich, and EPFL, 2015.

Alexander, C. and Korovilas, D., Understanding ETNs on VIX Futures, 2012. doi:10.2139/ssrn.2043061.

Asness, C., Moskowitz, T. and Pedersen, L., Value and momentum everywhere. J. Finance, 2013, 68, 929-985.

Bakshi, G. and Kapadia, N., Delta hedged gains and the negative market volatility risk premium. Rev. Financ. Stud., 2002, 16(2), 527-566.

Becker, R. and Clements, A., Are combination forecasts of S\&P 500 volatility statistically superior? Int. J. Forecast., 2008, 24, 122 133.

Becker, R., Clements, A.E. and White, S.I., Does implied volatility provide any information beyond that captured in model-based volatility forecasts? J. Bank. Finance, 2007, 31(8), 2535-2549. doi:10.1016/j.jbankfin.2006.11.013.
Bekaert, G. and Hoerova, M., The VIX, the variance premium and stock market volatility. J. Econom., 2014, 183(2), 181-192.

Blair, B., Poon, S.H. and Taylor, S., Forecasting S\&P 100 volatility: The incremental information content of implied volatilities and high frequency index returns. J. Econom., 2001, 105, 5-26.

Blume, M.E., Unbiased estimators of long-run expected rates of return. J. Am. Stat. Assoc., 1974, 69(347), 634-638. doi:10.1080/01621459.1974.10480180.

Bollerslev, T., Tauchen, G. and Zhou, H., Expected stock returns and variance risk premia. Rev. Financ. Stud., 2009, 22, 4463.

Brunnermeier, M. and Pedersen, L., Market liquidity and funding liquidity. Rev. Financ. Stud., 2009, 22, 2201-2238.

Buraschi, A. and Jackwerth, J., The price of a smile: Hedging and spanning in option markets. Rev. Financ. Stud., 2001, 14(2), 495527.

Byoun, S., Chuck, C.Y. and Park, Y.H., Expectation hypothesis of the term structure of implied volatility: Evidence from foreign currency and stock index options. J. Financ. Econom., 2002, 1, $126-151$

Campa, J. and Chang, K., Testing the expectations hypothesis on the term structure of volatilities in foreign exchange options. $J$. Finance, 1995, 50(2), 529-547.

Coval, J. and Shumway, T., Expected option returns. J. Finance, 2001, 56(3), 983-1009.

Dew-Becker, I., Giglio, S., Le, A. and Rodriguez, M., The price of variance risk. J. Financ. Econ., 2017, 123(2), 225-250.

Dreschsler, I. and Yaron, A., What's vol got to do with it? Rev. Financ. Stud., 2011, 24(1), 1-45.

Eraker, B. and Wu, Y., Explaining the negative returns to volatility claims: An equilibrium approach. J. Finan. Econ., July, 2017, 125(1), 72-98.

Fama, E. and French, K., Common risk factors in the returns on stocks and bonds. J. Financ. Econ., 1993, 33, 3-56.

Fama, E. and French, K., Business cycles and the behavior of metal prices. J. Finance, 1998, 43, 1075-1093.

Fleming, J., The quality of market volatility forecasts implied by S\&P 100 index option prices. J. Empir. Finance, 1998, 5, 317345.

Froot, K., New hope for the expectations hypothesis of the term structure of interest rates. J. Finance, 1989, XLIV(2), 283-305.

Gorton, G., Hayashi, F. and Rouwenhorst, K., The fundamentals of commodity futures returns. Rev. Finance, 2013, 17, 35-105.

Gromb, D. and Vayanos, D., Equilibrium and welfare in markets with financially constrained arbitrageurs. J. Financ. Econ., 2002, 66, 361-407.

Heston, S., A closed-form solution for options with stochastic volatility with applications to bond and currency options. Rev. Financ. Stud., 1993, 6(2), 327-343.

Hull, J. and White, A., The pricing of options on assets with stochastic volatility. J. Finance, 1987, 42, 281-300.

Johnson, T., Risk premia and the VIX term structure. J. Financ. Quant. Anal., 2016, forthcoming.

Konstantinidi, E. and Skiadopoulos, G., Are VIX futures prices predicable? An empirical investigation. Int. J. Forecast., 2011, forthcoming.

Konstantinidi, E., Skiadopoulos, G. and Tzagkaraki, E., Can the evolution of implied volatility be forecasted? Evidence from European and US implied volatility indices. J. Bank. Finance, 2008, 32, 2401-2411.

Lin, Y., Pricing VIX futures: Evidence from integrated physical and risk-neutral probability measures. J. Futures Markets, 2007, 27, 1175-1217.

Lu, Z. and Zhu, Y., Volatility components: The term structure dynamics of VIX futures. J. Futures Markets, 2010, 30(3), 230-256.

Luo, X. and Zhang, J., The term structure of VIX. J. Futures Markets, 2012, 32(12), 1092-1123.

Matthias, F., Longstaff, F. and Lustig, H., The tips-treasury bond puzzle. J. Finance, 2013, 69(5), 2151-2197.

Mixon, S., The implied volatility term structure of stock index options. J. Empir. Finance, 2007, 14(3), 333-354. 
Nossman, M. and Wilhelmsson, A., Is the VIX futures market able to predict the VIX index? A test of the expectations hypothesis. $J$. Altern. Investments, 2009, 12(2), 54.

Pan, J., The jump risk premia implicit in options: Evidence from an integrated time-series study. J. Financ. Econ., 2002, 63(1), 3-50.

Poon, S. and Granger, C., Forecasting volatility in financial markets: A review. J. Econ. Lit., 2003, XLI, 478-539.

Poteshman, A., Underreaction, overreaction, and increasing misreaction to information in the options market. J. Finance, 2002. doi:10.1111/0022-1082.00348.

Schwager, J., A Complete Guide to the Futures Markets, 1984 (John Wiley \& Sons, Inc: New York).

Sepp, A., Pricing options on realized variance in Heston model with jumps in returns and volatility. J. Comput. Finance, 2008, 11(4), $33-70$.
Shiller, R., The volatility of long-term interest rates and expectations models of the term structure. J. Pol. Econ., 1979, 87(6), 11901219.

Stein, J., Overreactions in the options markets. J. Finance, 1989, 44, 1011-1023.

Szymanowska, M., De Roon, F., Nijman, T. and Goorbergh, R., An anatomy of commodity futures risk premia. J. Finance, 2014, 69, 453-482.

Zhang, J. and Huang, Y., The CBOE S\&P 500 three-month variance futures. J. Futures Markets, 2010, 30(1), 48-70.

Zhang, J. and Zhu, Y., VIX futures. J. Futures Markets, 2006, 26, 521-531.

Zhu, Y. and Zhang, J., Variance term structure and VIX futures pricing. Int. J. Theor. Appl. Finance, 2007, 10(1), $111-127$. 